Copyright

by

Yue Sun

2017 
The Dissertation Committee for Yue Sun

certifies that this is the approved version of the following dissertation:

\section{Do Customers Learn from Stock Prices?}

Committee:

Laura Starks, Supervisor

Aydogan Alti

Cesare Fracassi

Michael Sockin

Jason Abrevaya 


\title{
Do Customers Learn from Stock Prices?
}

\author{
by \\ Yue Sun, BBA
}

\section{DISSERTATION}

Presented to the Faculty of the Graduate School of

The University of Texas at Austin

in Partial Fulfillment

of the Requirements

for the Degree of

DOCTOR OF PHILOSOPHY

THE UNIVERSITY OF TEXAS AT AUSTIN

May 2017 
Dedicated to my husband Tie. 


\section{Acknowledgments}

I am most indebted to members of my dissertation committee: Laura Starks (chair), Aydogan Alti, Cesare Fracassi, Michael Sockin, and Jason Abrevaya. I also thank Andres Almazan, Jonathan Cohn, Andres Donangelo, Inessa Liskovich, Clemens Sialm, Sheridan Titman, Mindy Xiaolan Zhang, and participants at the 2016 EconCon (Princeton), the 2016 FMA Special Ph.D. Presentation Sessions and Doctoral Student Consortium (Las Vegas), the Ph.D. Poster Session at the 13th Annual Corporate Finance Conference (WUSTL), and research seminars at UT-Austin, London Business School, Washington University in St. Louis, University of Maryland, Texas A\&M University, University of Georgia, and Boston College for their insightful suggestions and comments. 


\title{
Do Customers Learn from Stock Prices?
}

\author{
Publication No. \\ Yue Sun, Ph.D. \\ The University of Texas at Austin, 2017 \\ Supervisor: Laura Starks
}

This dissertation provides evidence that a firm's stock price movements affect its customer demand. I develop a model in which customers learn about a firm's product quality partially from its stock price. This learning induces feedback from the price to customer demand. Furthermore, the firm manager adjusts product launch decisions in anticipation of these demand shifts. Consistent with the model's implications, I find that non-fundamental price declines due to mutual fund redemptions reduce sales and online customer interest. This depressed demand is accompanied by a lower probability of product launches. My findings underscore the real effects of financial market prices. 


\section{Table of Contents}

Acknowledgments $\quad$ v

Abstract vi vi

List of Tables $\quad$ ix

List of Figures $\quad$ x

Chapter 1. Introduction 1

1.1 Overview ....................... 1

1.2 Literature Review . . . . . . . . . . . . . . . 7

$\begin{array}{lll}\text { Chapter 2. Economic Setting } & 11\end{array}$

2.1 Model Description . . . . . . . . . . . . . . . . 11

2.2 Financial Market Equilibria . . . . . . . . . . . . . . . . 13

2.3 Feedback Effects of Stock Prices on Customer Demand . . . . 15

2.4 Feedback Effects of Stock Prices on Product Launch Decisions 17

2.5 Comparison between the Two Equilibria . . . . . . . . . . . . 19

Chapter 3. Empirical Analysis $\quad 22$

3.1 Data and Empirical Methodology . . . . . . . . . . . . . . 22

3.1.1 Measures of Customer Demand . . . . . . . . . . . 22

3.1 .2 Instrument for Stock Returns . . . . . . . . . . . . 27

3.1.3 Empirical Specification . . . . . . . . . . . . 31

3.2 Main Results . . . . . . . . . . . . . . . . . 33

3.2.1 Effects of Stock Returns on Sales . . . . . . . . . . . 33

3.2.2 Effects of Stock Returns on Online Customer Interest . 37

3.2.3 Heterogeneous Effect across Online Financial Interest . . 39

3.2.4 Cross-Industry Variations . . . . . . . . . . . . . . . . 41 
3.2 .5 Dynamic Effects . . . . . . . . . . . . . . . . 43

3.2.6 Nearest-Neighbor Matching Analyses . . . . . . . . . . . 44

3.2 .7 Additional Robustness Tests . . . . . . . . . . . . 46

3.2.8 Alternative Explanations . . . . . . . . . . . . . . 48

3.3 Firm Response to Customer Learning: Product Launch Decisions 51

3.3.1 Data on Product Launches . . . . . . . . . . . . 51

3.3.2 Effects of Stock Returns on Product Launch Probability 52

3.4 Conclusion . . . . . . . . . . . . . . . . 54

$\begin{array}{ll}\text { Appendices } & 74\end{array}$

$\begin{array}{lll}\text { Appendix A. Proofs } & \mathbf{7 5}\end{array}$

1 Proof of Proposition 1. . . . . . . . . . . . 75

2 Proof of Proposition 2 and the Model without Customer Learning from Stock Prices . . . . . . . . . . . . 76

3 Proof of Corollary $1 \ldots \ldots \ldots \ldots \ldots \ldots$

4 Proof of Proposition $3 \ldots \ldots \ldots \ldots$

$\begin{array}{ll}\text { Appendix B. Data Details } & 80\end{array}$

1 Google Trends Data Collection . . . . . . . . . . . . . . 80

2 Construction of the Instrument MFFlow . . . . . . . . . . 81

3 RavenPack News Analytics . . . . . . . . . . . . . . . 82

$\begin{array}{ll}\text { Bibliography } & 85\end{array}$

$\begin{array}{ll}\text { Vita } & 91\end{array}$ 


\section{List of Tables}

1 Variable Definitions and Summary Statistics . . . . . . . . 62

2 Effects of Stock Returns on Sales . . . . . . . . . . . . . . 64

3 Effects of Stock Returns on Online Customer Interest . . . . . 65

4 Heterogeneous Effects across Online Financial Interest . . . . 66

5 Effects of Stock Returns on Sales by Industry _. . . . . . . 67

6 Dynamic Effects of Large Mutual Fund Redemption Shocks on Sales and Online Customer Interest . . . . . . . . . . . . . . . 69

7 Nearest-Neighbor Matching Analyses . . . . . . . . . . . 70

8 Robustness Tests . . . . . . . . . . . . . . . 71

9 Alternative Explanations . . . . . . . . . . . . . . . 72

10 Effects of Stock Returns on Product Launch Probability . . . 73 


\section{List of Figures}

1 Volatility of the Stock Price . . . . . . . . . 56

2 Online Customer Interest for Apple Inc. . . . . . . . . . . . 58

3 Effects of Large Mutual Fund Redemption Shocks on Stock Returns . . . . . . . . . . . . . . . . . . . 59

4 Effects of Large Mutual Fund Redemption Shocks on Sales and Online Customer Interest . . . . . . . . . . . . . . . 60 


\section{Chapter 1}

\section{Introduction}

\subsection{Overview}

The extent to which financial market prices convey information to real decision makers has intrigued economists for decades. Such feedback from prices can explain otherwise puzzling patterns in asset prices and business cycles, but direct micro-level evidence is relatively scarce. The few existing empirical studies primarily focus on demonstrating that managerial learning from stock prices affects firms' financing and investment decisions. ${ }^{1}$ Anecdotal evidence, however, suggests that corporate executives are also concerned about potential negative spillovers from stock market undervaluation to customer decisions. $^{2}$ Guided by a parsimonious theoretical model featuring customer learning from stock prices, this paper evaluates whether customer demand responds to stock price movements using novel data and an instrumental variable design. I also assess whether firm managers incorporate such shifts in demand when making product launch decisions.

\footnotetext{
${ }^{1}$ See Bond et al. (2012) for a comprehensive survey of this literature, dating back to Hayek (1945). A detailed literature review is provided in the next section.

${ }^{2}$ Several public companies recently filed lawsuits against hedge funds, claiming that price manipulation by the defendants caused severe damage to the plaintiffs reputations, product sales, relationships with stakeholders, etc. These companies include Biovail Corporation, Fairfax Financial Holdings, and Overstock.com, among many others.
} 
A priori, because stock prices aggregate market participants' private information, the collective wisdom revealed in prices should provide valuable incremental information to customers. ${ }^{3}$ However, empirically identifying this relationship is challenging due to the lack of detectable exogenous variation in stock prices and precise measures of customer purchase decisions. I address these concerns by isolating price pressure induced by non-discretionary mutual fund redemptions and collecting a direct and high-frequency measure of customer demand from Google Trends. In the instrumental variable regressions, I find that a firm's underperformance in the stock market leads to lower sales and lower shopping-related Google search volume, which suggests that customers negatively update their evaluation of the firm's products from the unfavorable stock price signals. Further strengthening the learning explanation, these effects are more pronounced when more potential customers are aware of the firm's stock price (i.e., online financial interest in the firm is higher). Lastly, I present evidence that the fund outflow-induced price pressure also lowers a firm's product launch probability, which implies that firm managers take the customer learning into account when making product launch decisions.

To formalize the customer learning mechanism and deliver testable implications, I develop a theoretical model with feedback effects from a firm's stock price to its product demand. In the model, the firm offers a product with uncertain quality. Conceptually, product quality can be interpreted as attributes that affect the total value a customer can derive from the prod-

\footnotetext{
${ }^{3}$ This paper studies both business and individual customers.
} 
uct, including durability, popularity, maintenance, and future complementary products. Product demand is determined by a representative customer's expectation about the quality, which is formed based on the firm's stock price as well as a private signal. ${ }^{4}$ The firm's stock trades in a competitive financial market consisting of speculators who are privately informed about the product quality. The supply of the stock is subject to an unobservable noise trader shock that represents trading due to non-fundamental reasons (Grossman and Stiglitz (1980)). In equilibrium, the stock price partially reveals speculators' private information and thus serves as a signal about product quality for the customer.

A natural prediction of the model is that the product demand declines when the firm's stock price is lower. However, this relationship can also be explained by mechanisms other than customer learning from stock prices (e.g., omitted variables and reverse causality). To address this challenge, I derive from the model a prediction that is unique to the customer learning channel. Specifically, I examine the effect of noise trading on product demand. While the intention of the customer is to extract information about product quality from the stock price, he inevitably misinterprets price declines caused by noise trading as negative signals about the product quality. This learning mistake occurs because noise trader shocks are not separately observable from the stock

\footnotetext{
${ }^{4}$ In the model, the firm's product demand is equivalent to its cash flow. The private signal of the customer simply represents the component in the cash flow that is unknown to the speculators. In reality, this private signal can be interpreted as all information about product quality that the customer obtains from sources other than the stock price or, more abstractly, as exogenous changes in customer tastes.
} 
price. As a result, unfavorable noise trader shocks lower the demand for the firm's product.

I test this prediction of the model using an instrumental variable introduced in Edmans et al. (2012). In particular, when mutual funds experience extreme outflows, the fund managers are forced to liquidate a portion of their portfolios within a short period of time, causing substantial negative price effects on the stocks commonly held by the distressed funds. To remove discretionary selling by the fund managers, I compute the hypothetical trades of the distressed funds, assuming that their existing holdings are sold proportionally to ex-ante portfolio weights. ${ }^{5}$ Furthermore, I show that there is no significant decline in a firm's stock return, sales or online customer interest before large mutual fund redemption shocks. These results serve as a rebuttal against the argument that fund outflows are caused by the underperformance of the portfolio stocks. Lastly, similar to the noise trader shock in the model, this instrument is not observed by potential customers in the concurrent period because mutual fund holdings and flows are disclosed to the public with a delay. When a firm's stock price is impacted by these mutual fund redemptions, customers, by mistake, negatively update their evaluation of the firm's product quality.

Using this instrument and data from Compustat, I first document a sig-

\footnotetext{
${ }^{5}$ I also exclude sector funds to avoid endogenous effects of industry trends and portfolio holdings with large negative ex-ante return contributions to alleviate the concern that fund outflows may be caused by poor performance of the holdings.
} 
nificant negative effect of fund outflow-induced price pressure on sales. Specifically, I estimate a two-stage least squares (2SLS) regression while controlling for a large set of ex-ante characteristics and firm and time fixed effects. The result suggests that during the sample period 1980 to 2014, a decrease of 10 percentage points in quarterly stock returns reduces the sales-to-assets ratio by $2.2 \%$ of its average level in the concurrent quarter. This negative effect sustains for up to four quarters and dissipates afterwards.

While the sales result is consistent with the view that stock price fluctuations affect customer purchase decisions, the possibility exists that this result could be explained by firms' operational changes due to managerial learning from stock prices and external financial constraints. ${ }^{6}$ I conduct a series of empirical analyses to address this concern. First, I obtain the shopping-related search volume index from Google Trends to proxy for online customer interest. This measure more precisely captures customer decisions and mostly avoids the confounding effects of changes in product pricing on dollar sales. The sample covers more than 2,000 firms from 2004 to 2014, which maintains the generality of the results. Using the same instrumental variable design as in the previous analysis, I find that online customer interest declines by $5.3 \%$ of its average level when the monthly stock returns decrease by 10 percentage points. Importantly, the responses in sales and online customer interest both occur during

\footnotetext{
${ }^{6}$ Specifically, firm operations may change in response to non-fundamental stock price fluctuations because the manager of the firm learns from stock price movements or external financing becomes more costly. Customers then adjust their demand because of these changes in the firm, instead of learning from the stock price.
} 
the same quarter or month as the mutual fund redemption shocks. These immediate effects are unlikely to be driven by firm-initiated changes (e.g., investment), which, given the substantial adjustment costs, should require more than one quarter to affect customer demand. ${ }^{7}$

To provide further evidence that supports the customer learning mechanism, I also explore the heterogeneity in the effects across ex-ante measures of online attention to the firm's stock. Intuitively, a necessary condition for potential customers to learn from the stock price is that they must first be aware of it. While the customer in the model always precisely knows the firm's stock price, customers in reality may have limited attention. Therefore, the customer learning channel predicts that the effects of the instrumented stock return on the sales-to-assets ratio and the shopping-related Google search volume should both be stronger when there are more finance-related Google searches for the company or more searches for the stock ticker of the company. My empirical tests confirm this hypothesis. It is worth noting that this result is difficult to reconcile with the aforementioned alternative explanations related to operational changes in the firm.

The effects of non-fundamental stock price variation on sales differ across industries. For example, the effect is sizable in the consumer durables industry, while insignificant in the consumer nondurables industry. This re-

\footnotetext{
${ }^{7}$ The main regressions examine customer demand in the concurrent period to avoid confounding effects. However, similar results are found if I instead use the lagged stock return and instrument, as suggested in Table 6 .
} 
sult implies that concerns about long-term maintenance may be an important reason for consumers to care about the producer's stock market performance. Furthermore, customer demand in industries with limited product differentiation should not be affected by non-fundamental stock price changes because customers have no need to learn about quality. Consistent with this hypothesis, I find no significant effects in the energy and chemicals industries. Although suggestive, the cross-industry analysis helps to paint a more complete picture about the process of customer learning from stock prices.

In the final section of this paper, I assess whether firm managers incorporate customer learning from stock prices in their decision making process. Specifically, my model predicts that the manager of the firm is less likely to launch a new product when noise trading adversely impacts the firm's stock price. Rather than learning about quality from the stock price, the manager simply wants to avoid the depressed customer demand triggered by lower stock returns. I test this hypothesis using data on press releases of new products and services. The result shows that when the instrumented stock return decreases by 10 percentage points, the monthly probability of product launches decreases by 0.89 percentage points (i.e., $9.1 \%$ of the average launch probability).

\subsection{Literature Review}

This paper contributes primarily to the literature that examines the real effects of financial market prices. In particular, I focus on testing the channel that real decision makers extract market participants' private information from 
stock prices and use it to facilitate their decisions. Theoretical studies on this topic include Dow and Gorton (1997), Subrahmanyam and Titman (1999), Subrahmanyam and Titman (2013), Khanna and Sonti (2004), Goldstein and Guembel (2008), Goldstein et al. (2013), Peress (2014), Edmans et al. (2015), and Sockin (2015), among many others. The main intuition of my model is similar to Subrahmanyam and Titman (2001) and Stoughton et al. (2001). In the former paper, the authors examine a theoretical model in which firms' stakeholders, including customers, make decisions conditional on the stock price. Their main point is that complementarities across stakeholders can generate cascades in the firm's fundamental value and stock price. The latter paper examines how customer learning about product quality from stock prices affects firms' IPO decisions. Compared with these two papers, my model jointly determines customer demand and the stock price in the secondary market while allowing for feedback effects from the stock price to the firm's cash flow. Furthermore, these two papers do not conduct empirical analyses to test whether customers learn from stock prices or the possible implications of this type of learning on firm decisions. Therefore, this paper, to my knowledge, is the first to provide direct empirical evidence that stock price fluctuations affect customer purchase decisions.

The empirical corporate finance literature that evaluates whether learning from stock prices affects decisions in the real economy has grown dramatically in the past decade. The earliest studies in this literature are Luo (2005), which shows that the market reaction to a merger and acquisition an- 
nouncement predicts the probability of deal completion, and Chen et al. (2007), which shows that the investment-Q sensitivity is higher when a firm's stock price is more informative. Subsequent studies strengthen these earlier findings by examining the relationship between cross-listing and managerial learning from stock prices (Foucault and Gehrig (2008), Foucault and Frésard (2012)), learning from peers' stock prices (Foucault and Fresard (2014)), and the time evolution of price informativeness (Bai et al. (2016)). Complementary evidence is also discovered by marketing researchers. In particular, Markovitch et al. (2005) find that in the pharmaceutical industry, firms whose stocks underperform relative to the industry average subsequently adopt different marketing strategies from the outperformers. Unlike my paper, these studies do not use an instrumental variable to address the endogeneity of stock prices; instead, they rely on predictable variations in learning intensity for identification. Other alternative identification strategies, including structural estimation (Bakke and Whited (2010)) and natural experiments that shock the source of information in stock prices (Edmans et al. (2016)), also lead to evidence supporting the view that firm mangers learn from stock prices.

The mutual fund redemption instrument used in this paper is first proposed in Edmans et al. (2012) to examine whether stock underpricing increases the likelihood of takeovers. Other papers that use price pressure induced by mutual fund flows to isolate exogenous variations in stock prices include Khan et al. (2012), Hau and Lai (2013), Dessaint et al. (2016), and Williams and 
Xiao (2016). ${ }^{8}$ The primary difference between my empirical findings and those in the existing literature is that I specifically examine customer learning from stock prices and its effects on firms' sales, online customer interest, and product launch decisions, while previous papers mainly focus on managerial learning and its effects on firms' investment and financing decisions.

\footnotetext{
${ }^{8}$ Williams and Xiao (2016) is another paper that emphasizes learning from stock prices by stakeholders instead of the firm's own managers. They show empirically that suppliers learn from customers' stock prices to guide their relationship-specific investments. My paper is distinct from theirs in terms of the direction of learning (i.e., mine is the reverse of theirs). Because of the different learning mechanism, I also examine different outcome variables and cross-sectional analyses. Furthermore, my empirical tests are motivated by and provide support for a theoretical model that explains the effects of customer learning from stock prices on firms' cash flows and product launch decisions.
} 


\section{Chapter 2}

\section{Economic Setting}

To concretely describe the economic mechanism of customer learning from stock prices, I develop a rational expectations model consisting of a firm, a customer and a competitive stock market similar to that in Grossman and Stiglitz (1980). In this section, I describe the setup of the model and derive testable implications.

\subsection{Model Description}

The firm in this model sells a product with quality $z$ to a representative customer (either a business or an individual) who does not have perfect information about z. Quality can be interpreted as the level of customer satisfaction with regard to the products or services now, or the reliability of the firm to provide maintenance and follow-ups in the long run. The prior distribution

of $z$ is given by $N\left(\bar{z}, v_{z}\right)$. The customer learns about the product quality from the firm's stock price $p$ and a private signal $\eta=z+\epsilon_{\eta}$ with $\epsilon_{\eta} \sim N\left(0, v_{\eta}\right)$. The cash flow generated by selling the product is determined by the customer's perception about $z$. Specifically, the firm's cash flow is given by

$$
f=E[z \mid p, \eta]
$$


where $E[\cdot \mid p, \eta]$ denotes the customer's expectation conditional on $p$ and $\eta$. The functional form of $f$ can be interpreted in two ways. First, when the perceived quality is high, customers are willing to pay a higher price per unit of the product, as they are able to derive more utility from it. Second, holding the product price constant, a higher perceived quality can attract more customers to purchase the product.

The financial market consists of a measure-one continuum of speculators with exponential utility. They allocate their wealth between a risk-free asset with zero net return and the risky equity issued by the aforementioned firm. The supply of the risky asset is $\bar{x}+x$, where $x \sim N\left(0, v_{x}\right)$ is the noise trader shock, representing trading due to non-informational reasons. The speculators are endowed with perfect information about the product quality $z .^{1}$ However, they still face the risk induced by the noise component in the customer's private signal $\left(\epsilon_{\eta}\right)$. This noise component can be interpreted literally as the inaccurate information about product quality that customers obtain from sources other than the firm's stock price or, more abstractly, as exogenous changes in customer tastes.

The timeline of the model is as follows. At date 1, the speculators trade the firm's stock. Their private information about the firm's product quality is impounded in the stock price. The customer forms his expectation about the

\footnotetext{
${ }^{1}$ This assumption is made to simplify the math. The empirical predictions of the model remain unchanged when the speculators are endowed with heterogeneous noisy signals about the product quality and also learn from the stock price.
} 
firm's product quality using his private signal as well as the firm's stock price.

At date 2, the cash flow of the firm is realized. The speculators then consume their terminal wealth.

$$
t=1 \quad t=2
$$

1. The speculators trade the firm's stock based on their perfect private information about the product quality.

2. The customer forms his expectation about the product quality based on his private signal $\eta$ and the stock price $p$.
1. The cash flow of the firm is realized.

2. The speculators consume their terminal wealth.

\subsection{Financial Market Equilibria}

I consider the set of equilibria in which the firm's stock price is linear in the product quality $z$ and the noise trader shock $x$. Given this structure, the signal on product quality derived from the stock price takes the form $\zeta=z+\epsilon_{\zeta}$, where $\epsilon_{\zeta}$ is distributed as $N\left(0, v_{\zeta}\right)$. Since the customer's expectation about $z$ depends on his private signal $\eta$ and the stock price signal $\zeta$, the cash flow of the firm can be rewritten as

$$
f=\frac{v_{z}^{-1} \bar{z}+v_{\zeta}^{-1} \zeta+v_{\eta}^{-1} \eta}{v_{z}^{-1}+v_{\zeta}^{-1}+v_{\eta}^{-1}} .
$$

The optimal level of demand for the firm's stock that solves the speculators' portfolio choice problem is given by

$$
q^{*}=\frac{E[f \mid z]-p}{a V[f \mid z]},
$$


where $a>0$ is the coefficient of risk aversion, $E[\cdot \mid z]$ denotes the speculators' expectation conditional on $z$, and $V[\cdot \mid z]$ is the corresponding conditional variance. Since the speculators have perfect information about the product quality $z$ and observe the public signal $\zeta$ derived from the stock price, the only component in the cash flow that is uncertain to them is the noise in the customer's private signal $\epsilon_{\eta}$. Thus, the speculators' expectation about the firm's cash flow $f$ and the corresponding conditional variance are given by

$$
E[f \mid z]=\frac{v_{z}^{-1} \bar{z}+v_{\zeta}^{-1} \zeta+v_{\eta}^{-1} z}{v_{z}^{-1}+v_{\zeta}^{-1}+v_{\eta}^{-1}} ; \quad V[f \mid z]=\frac{v_{\eta}^{-1}}{\left(v_{z}^{-1}+v_{\zeta}^{-1}+v_{\eta}^{-1}\right)^{2}}
$$

The equilibrium stock prices are solved using the market clearing condition:

$$
q^{*}=\bar{x}+x
$$

Proposition 1 specifies the equilibrium stock price. The proof is shown in the appendices.

PROPOSITION 1. There exist two rational expectations equilibria in which the stock price takes the form

$$
p=A+B z+C x
$$

where

$$
\begin{gathered}
A=\frac{v_{z}^{-1} \bar{z}}{v_{z}^{-1}+v_{\zeta}^{-1}+v_{\eta}^{-1}}-\frac{a v_{\eta}^{-1} \bar{x}}{\left(v_{z}^{-1}+v_{\zeta}^{-1}+v_{\eta}^{-1}\right)^{2}} \\
B=\frac{v_{\zeta}^{-1}+v_{\eta}^{-1}}{v_{z}^{-1}+v_{\zeta}^{-1}+v_{\eta}^{-1}}
\end{gathered}
$$

and

$$
C=-\frac{a\left(v_{\zeta}^{-1}+v_{\eta}^{-1}\right)}{\left(v_{z}^{-1}+v_{\zeta}^{-1}+v_{\eta}^{-1}\right)^{2}}
$$


The values of $v_{\zeta}$ that correspond to the two equilibria are given in the appendices.

In this model, there are two equilibria with different price informative-

ness. In the equilibrium with high $v_{\zeta}^{-1}$ (equilibrium 1 hereafter), the stock price depends more on the product quality $z$ and less on the noise trader shock $x$. The customer finds the stock price to be more informative and thus relies less on his private signal. From the perspective of the speculators, the unknown component of the firm's cash flow is the customer's private information. When the stock price is more informative and the customer allocates less weight to his private signal, the cash flow becomes less risky to the speculators. Their risk aversion leads them to trade more aggressively. (i.e., the speculators' demand for the stock is more sensitive to z.) As a result, more of their private information is impounded into the stock price. In other words, the stock price is more informative, which fulfills the customer's initial belief. In the equilibrium with low $v_{\zeta}^{-1}$ (equilibrium 2 hereafter), the opposite process occurs. The customer allocates less weight to the stock price signal and more weight to his private signal. The speculators trade less aggressively, since the cash flow becomes riskier. As a result, the stock price is less informative.

\subsection{Feedback Effects of Stock Prices on Customer De- mand}

Since the customer uses the stock price as a signal to form his expectation about quality, demand for the firm's product should increase in the firm's 
stock price. However, a positive correlation between the customer demand and the stock price exists even when the customer does not learn from the stock price. This is because the customer and the speculators have correlated information regarding the product quality. Changes in product quality (i.e., fundamental shocks) can lead to covariation between the customer demand and the stock price. To derive testable implications that are unique to customer learning from stock prices, I examine how noise trader shocks (i.e., nonfundamental shocks) affect customer demand. Intuitively, when the customer extracts information about the firm's product quality from its stock price, he is unable to distinguish a price drop caused by inferior quality from a price drop caused an unfavorable noise trader shock. Therefore, non-fundamental variations in the stock price can also induce changes in customer demand. Proposition 2 formalizes this prediction. In the appendices, I solve the model in which the customer ignores the stock price signal $\zeta$. A comparison between the two models suggests that the prediction in Proposition 2 is true only when the customer learns from the stock price.

PROPOSITION 2. Demand for the firm's product (equivalently, the firm's cash flow) decreases in the noisy supply of its stock, that is,

$$
\frac{\partial f}{\partial x}<0
$$

if and only if the customer learns from the stock price. 


\subsection{Feedback Effects of Stock Prices on Product Launch Decisions}

In this subsection, I extend the model to examine whether and how customer learning from stock prices affects firm decisions. In particular, the manager of the firm decides whether to launch a new product. The quality of the new product is the same as the existing one but offering a new product allows the firm to tap into a different market. ${ }^{2}$ The representative customer for the new product is endowed with the same private signal $\eta$ about the firm's product quality as the existing customer. The cash flow generated by selling the new product is given by $g=E[z \mid p, \eta]$. The fixed launching cost is $k$. Following Subrahmanyam and Titman (2001), I assume that the firm's equity is issued only on the cash flow generated by the existing product $(f)$ to simplify the computation. As the insider, the manager of the firm has perfect information about the product quality $z$, but she is unable to credibly communicate the true quality to the customer. Let $L$ denote the indicator variable for the product launch decision. The manager chooses to launch the product (i.e., $L=1$ ), if the expected cash flow generated by the new product exceeds the launching cost (i.e., $E[g \mid z] \geq k$ ). Suppose that before making the launch decision, the manager of the firm randomly draws a fixed launching cost $k$ from the distribution $\operatorname{Unif}(\underline{k}, \bar{k})$. The unconditional probability of a

\footnotetext{
${ }^{2}$ The implications of the model are similar when the quality of the new product is imperfectly correlated with the existing product.
} 
product launch is given by

$$
\operatorname{Prob}[L=1]= \begin{cases}0 & \text { if } E[g \mid z]<\underline{k} \\ \frac{E[g \mid z]-\underline{k}}{\bar{k}-\underline{k}} & \text { if } \underline{k} \leq E[g \mid z]<\bar{k} \\ 1 & \text { if } E[g \mid z] \geq \bar{k}\end{cases}
$$

Given this setup, the manager faces no uncertainty caused by noise trading when making the product launch decision. Specifically, since the manager is privately informed about the true quality $z$ and observes the public stock price signal $\zeta$, she can easily compute the noise trader shock $x$. Nevertheless, the product launch decision will still respond to $x$. The manager follows the market because of the communication barriers between her and the customer. In particular, since the customer has an imperfect signal about the product quality, he extracts additional information from the stock price. As implied by Proposition 2, when a shock increases the noisy supply of the firm's stock, the stock price and, consequently, customer demand for the product decline. Knowing this effect, the manager of the firm is less willing to launch a new product even though she knows that the quality of the product is unchanged. In Corollary 1, I formally demonstrate the relationship between the product launch probability and the noise trader shock $x$.

COROLLARY 1. When the manager of the firm anticipates the effect of customer learning from stock prices on product demand, the firm's product launch probability is non-increasing in the noisy supply of its stock, that is,

$$
\frac{\partial \operatorname{Prob}[L=1]}{\partial x} \leq 0
$$




\subsection{Comparison between the Two Equilibria}

In this section, I analyze the differences between the two equilibria in terms of real decision efficiency and stock price volatility. As discussed earlier, the main difference between the two equilibria is the price informativeness. To understand real decision efficiency, I examine the ex ante expected net cash flow of the product launch, which can be expressed as

$$
\int_{k}^{\infty}(E[g \mid z]-k) d F(E[g \mid z]),
$$

where $F(E[g \mid z])$ denotes the cumulative distribution function of $E[g \mid z]$. Because the customer learns from the stock price, higher price informativeness leads to stronger feedback from the stock market to the firm's cash flow. From the manager's perspective, the expected cash flow generated by the new product $E[g \mid z]$ is more volatile ex ante. Furthermore, the opportunity to launch a new product can be viewed as a real option. The value of the option should increase in the volatility of the underlying asset. Therefore, the quantity in equation (2.7) is greater in equilibrium 1. In other words, the manager of the firm prefers the equilibrium with higher price informativeness. Proposition 3 formalizes this theoretical result. The proof is shown in the appendices.

PROPOSITION 3. The real decision efficiency, as measured by the ex ante expected net cash flow of the product launch, is greater in the equilibrium with higher price informativeness.

Next I analyze the two equilibria in terms of stock price volatility. Given

the expression of the stock price shown in Proposition 1, the unconditional 
variance of the stock price can be written as

$$
V[p]=B^{2} v_{z}+C^{2} v_{x} .
$$

As discussed earlier, in the equilibrium with higher price informativeness, the cash flow is less uncertain to the speculators. In other words, the conditional variance $V[f \mid z]$ is relatively low. Therefore, the speculators can better take actions to offset the noise trader shocks, and consequently better stabilize the stock price. However, the higher price informativeness also strengthens customer learning and the feedback effect, which results in more volatile cash flow and stock price. Since these two types of effects counteract each other, which equilibrium has a higher stock price volatility depends on the parameter values.

In Figure 1, I plot the price volatility given different parameter values. In the first graph, I fix $a$ and $v_{z}$, and examine how changes in $v_{\eta}$ and $v_{x}$ affect the relative levels of price volatility in the two equilibria. Specifically, I consider the case when $a=2$ and $v_{z}=2$. When the variance of the noise trader shock $v_{x}$ is higher, the first type of effect (i.e., higher price informativeness increases speculators' ability to offset noise trader shocks and stabilize price) is more likely to dominate. Therefore, equilibrium 1, which has a more informative stock price, is likely to have a lower price volatility. When the variance of the customer's private signal $v_{\eta}$ is higher, the volatility of the stock price tends to be higher in equilibrium 1 . This is because the customer learns more from the stock price when his private signal is less precise, which intensifies the feedback 
from the stock market to the firm's cash flow. Thus, the second type of effect (i.e., higher price informativeness leads to more volatile cash flow and stock price through the feedback mechanism) is more likely to dominate.

In the second graph, I increase the risk aversion coefficient to $a=4$. As shown, the region in which equilibrium 1 has a higher price volatility than equilibrium 2 shrinks. This is because the same amount of reduction in $V[f \mid z]$ leads to a larger change in the stock demand of a more risk averse speculator. Therefore, the first type of effect tends to dominate. Alternatively, keeping the risk aversion at $a=2$, when I decrease the prior variance $v_{z}$ to 0.4 in the third graph, equilibrium 1 always has a higher price volatility than equilibrium 2. In the last graph, when I increase $v_{z}$ to 4 , equilibrium 1 always has a lower price volatility. The intuition behind this result is that an increase in price informativeness leads to a larger reduction in the conditional variance $V[f \mid z]$ when $v_{z}$ is relatively high. Therefore, the first type of effect is likely to be stronger.

[Insert Figure 1 Here.] 


\section{Chapter 3}

\section{Empirical Analysis}

\subsection{Data and Empirical Methodology}

Two empirical elements are essential for testing the main prediction of

the model (Proposition 2): measures of customer demand and an instrument to isolate non-fundamental stock price changes. In this section, I discuss these empirical elements in detail, including data sources, variable construction, and descriptive statistics. Furthermore, I present the empirical specification used to assess whether customer purchase decisions are affected by the stock market performance of firms.

\subsubsection{Measures of Customer Demand}

A great obstacle to empirically assessing whether customers respond to stock price fluctuations is the lack of large-scale, high-frequency data on purchase behaviors. While researchers in marketing and industrial organization have collected some high-quality datasets on customer buying decisions, these datasets usually each focus on a small number of firms in a particular industry during a short time period. This type of dataset rarely allows enough plausibly exogenous variation in stock prices, restricting the statistical power of the tests. Furthermore, it is often questionable whether results derived in a spe- 
cific setting can be generalized to other environments. This study overcomes these limitations by using two complementary measures of customer demand available for a large sample of firms: sales from Compustat quarterly files and shopping-related online search volume indices from Google Trends. The first measure captures the real effect of customer learning from stock prices on firms, while the second measure more precisely gauges immediate and direct responses by customers and is less likely to be affected by changes in firm operations. Since the sales data are obtained from a standard data source (i.e., Compustat), I omit further description to preserve space. In the rest of this subsection, I illustrate the collection process of the Google Trends data.

Google Trends is a service provided by Google Inc. that tracks online search frequencies of user-specified terms. Since its initiation in 2004, Google Trends data have been applied in various fields of academic research. For example, existing finance studies (e.g., Da et al. (2011) and Madsen and Niessner (2016)) use the search volume index $(S V I)$ on the stock ticker of a firm to capture retail investor attention. Marketing researchers also use Google searches to measure prepurchase information acquisition by customers (e.g., Hu et al. (2014)). In this study, rather than simply requesting an index summarizing all searches containing the name of a given company, I adopt two advanced functions of Google Trends to obtain a more precise measure of customer interest: the topic report function and the categorization function. The topic report function helps to exclude searches on potential alternative meanings of a company's name and include other searches related to the company, such 
as searches on alternative or misspelled names, subsidiaries, and products. Specifically, I apply an automated script to request all topics suggested by Google using the name of a company as the search term. The script then collects the SVIs on topics categorized as "company", "business operation", "corporation", or words with similar meanings. For example, as shown in the top image in Figure 2, when the word "apple" is used as the search input, a number of topics are suggested by Google. The automated script collects the SVI on the topic labeled as "technology company". If I instead request a report on the word "apple" without specifying a topic, the resulting index would be based on all searches containing the string "apple", including searches on literal apples (i.e., the fruit). Furthermore, when a topic report is requested, Google uses a proprietary algorithm to combine many search queries related to the topic. In the previous example, the search volume index on "apple technology company" also summarizes searches containing misspellings (e.g., "appl"), and searches on products of the firm (e.g., Apple TV and iPhone). Although the topic report function can clearly measure searches related to a company, it cannot separately identify customer interest from other types of online interest. To address this concern, I refine the SVI by selecting the "shopping" category, as shown in the bottom image in Figure 2. Hu et al. (2014) also use the categorization function to isolate customer interest.

[Insert Figure 2 Here.]

Admittedly, the shopping-related SVI (SVIShop) is not a perfect mea- 
sure of customer demand. Specifically, SVIShop may erroneously include other types of online interest rather than customer interest. One factor of particular concern is that investors may search a company to facilitate their financial decisions. Thus, stock returns may appear to influence the SVIShop of a company because investors, rather than customers, respond to price fluctuations. This concern is alleviated by including the $S V I$ of a company in the "finance" category (SVIFin) as a control variable in the regressions that examine the effect of stock returns on online customer interest. ${ }^{1}$ I also control for the media coverage of a firm to absorb its effect on customer attention. The variable NewsNum is the total number of news reports on a firm in a given month, obtained from RavenPack News Analytics. Other control variables consist of characteristics that are expected to have explanatory power on the product demand of a firm: firm age, market capitalization (a proxy for firm size), advertising expense ratio, cost of goods sold ratio, research and development $(\mathrm{R} \& \mathrm{D})$ ratio, capital expenditure rate, and industry concentration. Lastly, I include the firm's leverage ratio and cash flow rate to control for the potential effects of financial constraints on customer demand. These variables are computed using CRSP and Compustat data. Detailed definitions are provided in Panel A of Table 1.

In Panel B of Table 1, I first present the summary statistics for the sam-

\footnotetext{
${ }^{1}$ An alternative approach is to use the $S V I$ of a firm's ticker (SVITic) as a proxy for online financial interest, following Da et al. (2011). However, SVIFin captures broader interest in a firm's financial information. Furthermore, it has a much higher statistical correlation with SVIShop than SVITic. Therefore, using SVIFin as a control is more conservative. The results are similar when SVITic is used, instead.
} 
ple used in the sales analysis. I begin with all firms in the CRSP/Compustat merged database during the sample period 1980 to 2014 with non-missing values for all variables used in the regressions. The sample firms are further required to have common stocks traded on the NYSE, AMEX, or NASDAQ exchange. Financials (SIC 6000-6999), utilities (SIC 4900-4999), and public administration (SIC 9000-9999) are excluded. Potentially unbounded variables are Winsorized at the $1 \%$ and $99 \%$ levels. After merging with the instrumental variable for stock returns discussed later, there are 311,368 firm-quarter observations and 10,017 distinct firms. The summary statistics of the variables are comparable with those in previous studies.

The collection process of the Google Trends data starts with the firms in the sample of the sales analysis during 2004 (the beginning period of Google Trends) to 2014. There are 4,809 firms in the initial sample. Among them, 2,133 firms have valid shopping-related search volume indices in Google Trends. More details regarding the construction of the dataset are provided in the appendices. In Panel C, I report the summary statistics of the sample used in the online customer interest analysis. The SVI downloaded from Google Trends ranges from 0 to 100. Since the index is only comparable within each firm, I include firm fixed effects in all regressions. The correlation between SaleToAst and SVIShop is 0.12 (statistically significant at the $1 \%$ level), which suggests that SVIShop is a reasonable proxy for online customer interest. In terms of media coverage, the average number of news reports per month for a given firm is 19.5. Since this variable is highly skewed, I 
log-linearize it in the regressions.

[Insert Table 1 Here.]

\subsubsection{Instrument for Stock Returns}

In addition to the data challenge, detecting the learning mechanism proposed in my model also requires an instrument that can isolate non-fundamental stock price changes (i.e., a proxy for the noise trader shock in the model). Specifically, a positive OLS estimate obtained by regressing product demand on stock returns does not necessarily imply that customers are learning from stock prices. This is because customers and traders usually have correlated information regarding the firm's fundamentals, which induces a positive correlation between demand and stock returns. Since we often cannot perfectly control for the customers' information, the OLS estimate is subject to an omitted variables bias. In addition, exogenous changes in customer tastes and measurement errors can lead to reverse causality and attenuation biases, further confounding the OLS estimate.

To isolate the causal effect of stock returns on customer demand, I rely on an instrumental variable proposed in Edmans et al. (2012) that captures plausibly exogenous variations in a firm's stock prices induced by mutual fund redemptions. The instrument is defined as

$$
M F \text { Flow }_{i, t}=-\frac{\sum_{f \in \Omega}\left[T N A_{f, t}-T N A_{f, t-1}\left(1+r_{f, t}\right)\right] w_{i, t-1}^{f}}{V o l_{i, t}},
$$


where $\Omega$ is the set of mutual funds with percentage flows less than the 10 th percentile of the sample (i.e., distressed funds), $T N A_{f, t}$ and $r_{f, t}$ are the assets under management and the net return of fund $f$ in period $t, V_{o l}, t$ is the dollar trading volume of stock $i$ in period $t$, and $w_{i, t-1}^{f}$ is the weight of stock $i$ in fund $f$ 's portfolio at the end of period $t-1 .^{2}$ I multiply the variable by -1 so that the resulting measure is a positive number. For final use in the regressions, I merge MFFlow with the CRSP database based on historical CUSIPs. Missing values of MFFlow are replaced with zeros for firms with positive mutual fund ownerships at the beginning of the period. More details regarding the construction of $M F F$ low are given in the appendices.

The instrument MFFlow is motivated by the finding first documented in Coval and Stafford (2007) (CS hereafter) that after extreme outflows of capital, mutual funds are forced to sell existing holdings, causing negative price pressure on stocks commonly held by such funds. However, rather than using the actual trading of the distressed funds, as in CS, MFFlow is computed by assuming that mutual funds sell their existing holdings proportionally to

\footnotetext{
${ }^{2}$ The instrument can be computed every quarter or every month. Although the holdings data are only available at the quarterly frequency, the mutual fund flows can be computed every month. To compute the MFFlow in month $t$, I use the holdings at the quarter end before month $t$. All quarterly regressions use quarterly MFFlow, while all monthly regressions use monthly MFFlow. The instrument is constructed using funds experiencing extreme negative flows and thus only captures negative price pressure. A similar measure can be constructed using funds experiencing extreme positive flows. However, as shown in Lou (2012), mutual funds tend to sell their existing holdings proportionally after experiencing negative flows but do not expand proportionally after experiencing positive flows. In other words, the instrument constructed using funds with extreme positive flows do not pass the relevance test.
} 
ex-ante portfolio weights after extreme outflows. I use the ex-ante weights of the distressed funds' portfolios to avoid capturing the discretionary selling by the fund managers. Actual fund trades after outflows are more endogenous, since fund managers are more likely to sell stocks with weaker fundamentals (Huang et al. (2016)). ${ }^{3}$

A further concern regarding the exogeneity of the instrument is that mutual fund flows are affected by the fundamentals of their underlying holdings. Specifically, if a fund invests in firms with lower customer demand, it is more likely to have poorer performance, resulting in outflows. This concern is particularly relevant for sector funds. During industry downturns, customer demand shrinks while investors withdraw capital from mutual funds specializing in the declining industries. Therefore, I exclude all sector funds from my sample. Among the diversified mutual funds, outflows may still be driven by the underperformance of a few concentrated positions. To address this issue, I compute the ex-ante return contribution of each position in a distressed fund's portfolio and remove the positions that have large negative return contributions. Specifically, if a fund experiences an extreme outflow from period $t-1$ to $t$, the ex-ante return contribution of stock $i$ in fund $f$ is computed as $w_{i, t-2}^{f} \times \operatorname{Return}_{i, t-1}$, where $w_{i, t-2}^{f}$ is the weight of stock $i$ in fund $f$ 's portfolio

\footnotetext{
${ }^{3}$ Huang et al. (2016) document that after extreme outflows, mutual fund managers are more likely to sell stocks with higher ex-ante short interest. The authors argue that short interest is a proxy for unobservable negative private signals, so the result suggests that fund managers choose to sell low-quality stocks after extreme outflows. By using the ex-ante portfolio weights, the instrument MFFlow used in this paper does not capture this type of selective selling by fund managers.
} 
at the end of period $t-2$, and Return $_{i, t-1}$ is the return of stock $i$ in period $t-1$. I exclude all positions with return contribution less than $-0.2 \%$ (roughly the 5th percentile in the sample). The remaining positions in the distressed fund's portfolio are unlikely to be the cause of the outflow, but these stocks could still experience negative price pressure because the distressed fund is forced to liquidate its portfolio to redeem the investors. ${ }^{4}$

In Figure 3, I show the cumulative average abnormal returns $(C A A R)$ around large mutual fund redemption shocks in the top graph, and the corresponding quarterly MFFlow in the bottom graph. Specifically, during the period 1980 to 2014 , I take the sample of common stocks that are traded on the NYSE, Amex, or NASDAQ exchange with non-missing values of MFFlow and define an event to be a firm-quarter during which MFFlow is above the 90th percentile of the quarter. Abnormal returns are computed using three different benchmarks: the CRSP equal-weighted index (red), the Fama-French equal-weighted 48 industry portfolios (blue), ${ }^{5}$ and the characteristic-matched portfolios proposed in Daniel et al. (1997) (green). The event window is from 12 months before to 18 months after. As shown in the plot, there is a significant decline of $4-5 \%$ in $C A A R$ during the event quarter, depending on the benchmark. Compared with the findings in CS, the price decline induced by my instrument is smaller in magnitude. Furthermore, in contrast to the down-

\footnotetext{
${ }^{4}$ Edmans et al. (2012) does not make this adjustment when constructing their instrument. My main findings are robust to using their original measure.

${ }^{5}$ The Fama-French industry definitions and portfolio returns used in this paper are obtained from Kenneth French's website.
} 
ward pre-trend shown in CS, there is no significant decline in $C A A R$ before the event in Figure 3, suggesting that these stocks are unlikely to be the cause of the mutual fund outflows.

[Insert Figure 3 Here.]

\subsubsection{Empirical Specification}

The main empirical prediction of the model is that non-fundamental fluctuations in a firm's stock price affect its product demand if and only if the representative customer learns from the stock price. The measure MFFlow can be considered as an empirical proxy of the noise trader shock $x$ in the model. Besides the relevance and exogeneity criteria discussed in the previous subsection, MFFlow must satisfy another assumption in order to be a valid proxy for $x$ : customers cannot distinguish a price movement caused by MFFlow from that caused by a fundamental shock. This assumption generally holds because mutual fund holdings and flows are disclosed to the public with a delay. Furthermore, customers would not be expected to pay close attention to the flows and holdings of the mutual funds that own a firm's stock, so they are unlikely to conduct the same analysis during their decision making process as an econometrician is able to do ex-post.

I test the main predictions of the model using the following 2SLS regressions:

First Stage: Return $_{i t}=b_{m}$ MFFlow Flt $_{i}+b_{c}$ Controls $_{i t-1}+e_{i t}$; 
Second Stage: Demand $_{i t}=\beta_{r} \widehat{\text { Return }}_{i t}+\beta_{c}$ Controls $_{i t-1}+\nu_{i t}$.

Return $_{i t}$ denotes the stock return of firm $i$ in period $t$. $\widehat{\text { Retur }} n_{i t}$ represents the fitted value of Return $_{i t}$ from the first stage. The dependent variable Demand De $_{\text {t }}$ in the second stage regression is a measure of customer demand (either the sales-to-assets ratio obtained from Compustat or the shopping-related search volume index obtained from Google Trends). I choose to examine the customer demand response in the period concurrent to the mutual fund redemption shocks to avoid confounding effects. Specifically, existing studies document that variables related to firm operations, such as investments (Hau and Lai (2013)), takeovers (Edmans et al. (2012)), and seasoned equity offerings (Khan et al. (2012)) change after non-fundamental shocks to the firm's stock price. A potential concern is that these operational changes affect customer demand. For example, if a firm reduces its R\&D after a mutual fund redemption shock, its customer demand may decline due to the lack of innovative products. Such an effect cannot be directly attributed to the learning mechanism described in my model. Examining the concurrent change in demand helps me sidestep this issue because firms typically face substantial adjustment costs when making operational changes. Variation in customer demand caused by changing firm operations is unlikely to manifest in the data during the same period as the MFFlow shock.

Based on my model's prediction and the graphic evidence in Figure 3, I expect the first stage coefficient on MFFlow, $b_{m}$, to be negative and statistically significant, that is, non-discretionary selling by distressed mutual 
funds reduces a firm's stock return. More crucial to testing whether customers learn from stock prices is the sign of the second stage coefficient on $\widehat{\operatorname{Retur}}{ }_{i t}$, $\beta_{r}$. Specifically, $\widehat{\operatorname{Retur}} n_{i t}$ represents the non-fundamental fluctuations in the stock price. As suggested in Proposition 2, if customers extract information about the product quality from the stock price, then these non-fundamental fluctuations affect customer demand, that is, $\beta_{r}$ is positive and statistically significant. Otherwise, $\beta_{r}$ should be insignificant.

\subsection{Main Results}

In this section, I present the main empirical findings of this study, starting with the effects of stock returns on sales and online customer interest. I also explore the heterogeneity across ex-ante firm characteristics and the dynamics of the effects to further shed light on the underlying mechanisms and distinguish the customer learning channel proposed in the model from alternative explanations.

\subsubsection{Effects of Stock Returns on Sales}

In Table 2, I assess the effects of stock price movements on firms' quarterly sales. Dollar sales are divided by lagged total assets to make the measure more comparable across firms of different sizes. Thus, the dependent variable is the sales-to-assets ratio (SaleToAst) (i.e., asset turnover). In column (1), I first examine the OLS regression of SaleToAst on Return, while control- 
ling for the firm characteristics mentioned in Subsection 3.13.1.1. ${ }^{6}$ Firm fixed effects are included to remove the time-invariant component of SaleToAst. Time fixed effects are used to account for potential confounding effects of macroeconomic conditions, such as financial crises. Standard errors are clustered by Fama-French 48 industry. ${ }^{7}$ The coefficient on Return implies that an increase of 10 percentage points in quarterly stock returns is associated with an increase of 0.41 percentage points in SaleToAst. Given that the average of SaleToAst is $31.5 \%$, the effect corresponds to an increase of $1.28 \%$. The coefficients on the control variables suggest that the capital expenditure rate and the cash flow rate are positively correlated with the sales-to-assets ratio, while the size of the firm and the $R \& D$ expense ratio are negatively correlated with it. As discussed earlier, the OLS estimate is subject to at least three types of biases. First, there may be omitted variables. For example, the approval of a new drug by the FDA improves a pharmaceutical company's sales while boosting its stock price, which results in an upward bias in the OLS estimate. Alternatively, when a negative shock hits the firm, the stock price suffers. At the same time, the manager may lower the product prices in hope to attract more customers and mitigate the effect of the negative shock on sales. In this case, the OLS estimate is biased downward. Furthermore, exogenous changes

\footnotetext{
${ }^{6}$ All control variables are lagged one period from the dependent variable. SVIFin and NewsNum are less relevant controls when examining SaleToAst as the outcome variable. Furthermore, they are only available since 2004. Therefore, I include these two control variables only in the online customer interest regressions, but not in the sales regressions.

${ }^{7}$ The results are robust to clustering by firm and double-clustering by firm and time. The results are available upon request. The industry-level clustering gives more conservative standard errors.
} 
in customer interest can directly affect stock returns, leading to reverse causality concerns. Lastly, some customers may infer a firm's product quality using alternative measures that reflect a firm's stock market performance, such as valuation ratios or risk-adjusted returns. In this sense, the raw stock return contains measurement errors, which bias the OLS estimate toward zero (i.e., the attenuation bias). In this regression, because the stock price is highly colinear with the control variables, the attenuation bias could be particularly severe (Wooldridge (2010), p. 81). Since various endogeneity concerns generate biases in opposite directions, whether the OLS estimate overstates or understates the true effect is an empirical question.

To address the endogeneity problems, I rely on the instrumental variable design proposed in Section 3.1.2. The first stage regression in column (2) suggests that MFFlow is strongly negatively correlated with Return, consistent with the graphic evidence in Figure 3. The high t-statistic on MFFlow implies that the instrument is not weak. The second stage coefficient on Return in column (3) suggests that decreases in stock returns induced by mutual fund redemptions reduce the firm's sales. Specifically, a decrease of 10 percentage points in instrumented Return leads to a decrease of 0.7 percentage points in SaleToAst. The effect represents $2.22 \%$ of the average SaleToAst and is statistically significant at the 1\% level. The 2SLS effect is slightly larger in magnitude than the OLS effect. In column (4), I examine the reduced form regression of SaleToAst on the instrument MFFlow. This specification gauges the effect of non-fundamental fluctuations in stock prices on 
customer demand and thus more directly tests the comparative statics shown in Proposition 2. The results suggest that for a one-percentage-point increase in MFFlow, the sales-to-assets ratio decreases by 0.16 percentage points.

\section{[Insert Table 2 Here.]}

Although the sales results are consistent with the story that customers' purchase decisions are influenced by firms' stock prices, existing evidence in the literature also suggests a few alternative explanations. In particular, firms may change their operations in response to non-fundamental stock price changes because of managerial learning from stock prices or external financial constraints. For example, investment in physical and human capital may decrease after MFFlow shocks because managers infer a negative technology shock based on stock prices or external financing becomes more costly. These operational changes can lead to subsequent decline in sales. As mentioned in Section 3.13.1.3, I partially address this concern by examining the changes in SaleToAst in the quarter concurrent to the MFFlow shocks. The reason is that most operational changes on the firm's side take considerable amount of time to implement. Thus, they are unlikely to affect sales in the contemporaneous period. Nevertheless, there may still be some short-term changes in the firm (e.g., depressed morale among sales staff or changes in product pricing) that could result in lower sales. To further safeguard against these alternatives, I examine a more direct and frequent measure of customer decisions: 
shopping-related Google search volume. The results are shown in the next subsection.

\subsubsection{Effects of Stock Returns on Online Customer Interest}

In Table 3, I examine whether negative price pressure induced by mutual fund redemptions leads to lower online customer interest, as proxied by SVIShop. Control variables are the same as described in Section 3.1.1. ${ }^{8}$ For the purpose of comparison, I first examine the OLS regression of SVIShop on Return. As expected, the coefficient on Return suggests that there is a robust positive correlation between stock returns and online customer interest. However, the OLS estimate is subject to endogeneity concerns similar to those in the sales analysis.

In columns (2) and (3), I estimate the 2SLS regressions in which Return is instrumented by MFFlow. The first stage coefficient on MFFlow is again negative and highly statistically significant. The second stage result implies that when the instrumented monthly stock return drops by 10 percentage points, the online customer interest declines by 1.51 units. The effect corresponds to $5.27 \%$ of the average SVIShop and is statistically significant at the $5 \%$ level. The coefficients on the control variables are largely consistent with intuition. Financial interest, media coverage, firm age, and firm size are positively correlated with online customer interest. In terms of firm operational

\footnotetext{
${ }^{8}$ Control variables are lagged by one period. If the control variable is only available at the quarterly frequency, the customer interest in month $t$ is matched with the control variable at the quarter end before month $t$.
} 
decisions, higher advertising expense and cost of goods sold ratios are linked to higher customer interest, as expected. Surprisingly, the R\&D expense ratio is negatively associated with SVIShop. One possible explanation is that R\&D efforts require more than one quarter to materialize into marketable products that attract customer attention. Firms with recent high R\&D spending may therefore have lower customer interest because they do not have products to deliver yet. The last two control variables are intended to capture the effects of financial constraints. As suggested by the coefficients on Leverage and CashFlow in column (3), higher ex-ante measures of financial constraints are actually associated with higher customer interest in my sample. This observation seems to be inconsistent with the alternative explanation that the 2SLS coefficient on Return includes the confounding effects of financial constraints. In column (4), I directly assess the effect of MFFlow on SVIShop. The result implies that for a one-percentage-point increase in MFFlow, SVIShop decreases by 0.15 units.

[Insert Table 3 Here.]

Overall, the results in Tables 2 and 3 suggest that negative price pressure caused by mutual fund redemptions reduces customer demand. The effect is consistent with the learning mechanisms described in the model. In particular, customers infer the firm's product quality from its stock price fluctuations. When mutual fund redemptions push the firm's stock price down, customers, who are unable to distinguish price declines caused by non-fundamental shocks 
from those caused by unfavorable quality shocks, negatively update their assessment of the firm's products. As shown in the model, these real effects of noise trader shocks exist only when customers base their purchase decisions on information extracted from stock prices.

\subsubsection{Heterogeneous Effect across Online Financial Interest}

A necessary condition for the customer learning mechanism to hold is that potential customers must be aware of the stock price fluctuations of a firm. In contrast, the alternative explanations related to changes in firm operations do not require the same condition. I rely on this distinction to provide strengthening evidence on the customer learning channel. Specifically, I test whether the effects of non-fundamental stock price changes on sales and online customer interest are stronger when online financial interest in the firm is higher. ${ }^{9}$ To do so, I first add an interaction term between Return and a measure of financial interest in the second stage regression specified in equation (3.3). To instrument the additional endogenous variable, I further include the interaction term between MFFlow and the financial interest measure in the first stage regression in equation (3.2). Two alternative measures of financial interest are obtained from Google Trends. The first measure is the SVI on the Google topic of a given company in the "finance" category (SVIFin).

\footnotetext{
${ }^{9}$ In the model, customers essentially have unlimited attention and are able to respond to every small change in stock price. In reality, however, customers are swamped with various pieces of information and can only respond to the stock price changes that capture their attention.
} 
The second measure is the SVI on the stock ticker of a firm (SVITic). ${ }^{10}$ For illustration purposes, I construct a dummy variable for whether the financial interest measure is above the firm-level median and use the dummy variable in the interaction regression. Based on the customer learning channel, I expect that after instrumentation, the interaction between Return and the stock attention measure is positive and statistically significant.

Table 4 shows the results of the interaction regressions. In the first two columns, the dependent variable is the quarterly sales-to-assets ratio. ${ }^{11}$ Control variables (untabulated in the table for brevity) are the same as those used in Table 2. In column (1), the result suggests that if the financial interest in the firm is below the median (High SVIFin $=0$ ), then a 10-percentagepoint decrease in instrumented Return reduces SaleToAst by 0.54 percentage points. In contrast, if the financial interest is above median (High SVIFin $=1$ ), then the same amount of decrease in instrumented Return results in a reduction of 1.14 percentage points in SaleToAst. In other words, the effect of non-fundamental stock price changes on the sales-to-assets ratio more than doubles when the online financial interest in the firm is above the median. When SVITic is used as the proxy for financial interest in column (2), the results are similar. In the last two columns, I conduct the interaction regression using SVIShop as the dependent variable, while controlling for the same char-

\footnotetext{
${ }^{10}$ Da et al. (2011) and Madsen and Niessner (2016) provide evidence that SVITic is a good proxy for retail investor attention.

${ }^{11}$ There are fewer observations in the first two columns compared with the sample used in Table 2 because SVIFIn and SVITic are only available since 2004 for a subsample of firms.
} 
acteristics as in Table $3 .^{12}$ The coefficients on the interaction term are again positive and statistically significant, suggesting that stock price fluctuations induced by mutual fund redemptions have larger effects on online customer interest when the online financial interest in the firm is higher. In summary, the results in Table 4 are consistent with the customer learning channel proposed in my model but difficult to reconcile with alternative theories.

[Insert Table 4 Here.]

\subsubsection{Cross-Industry Variations}

In this subsection, I run the regressions in columns (1)-(3) of Table 2 using observations in each of the Fama-French 12 industries separately. ${ }^{13}$ The results are shown in Table 5. There are a few salient observations in this table. First, when examining the consumer nondurables and durables industries, the 2SLS coefficient on Return is only statistically significant in the latter. Previous studies in finance and marketing literatures (e.g., Hortaçsu et al. (2013) and $\mathrm{Hu}$ et al. (2014)) argue that consumer discretion is higher when considering buying durable goods (e.g., automobiles, appliances, and furniture), compared with nondurables (e.g., food and apparel). In the context of my story, when customers observe a lower stock return, they may update

\footnotetext{
${ }^{12}$ SVIFin is not included as a control because the dummy variable High SVIFin is inluded in the regressions.

${ }^{13}$ I do not tabulate the industry-level regressions using SV IShop as the dependent variable because the sample size is much smaller. There is limited statistical power after dividing the sample into Fama-French 12 industries.
} 
negatively about the firm's ability to provide warranties and complementary products in the future. This type of mechanism is more likely to manifest in the durable goods industry, in which follow-up services are highly valued by customers. The results in Table 5 are consistent with this expectation. Second, the instrumented stock return does not have any significant effect on the salesto-assets ratio in the energy and chemicals industries, in which products are commodity-like. In these industries, purchases are more likely to be driven by convenience or long-term relationships. Therefore, information provided by financial market prices does not play a significant role. In the rest of the industries, there are sizable effects of non-fundamental stock price fluctuations on sales in the industries of business equipment, ${ }^{14}$ telecommunications, and shops. In the manufacturing and healthcare industries, the 2SLS effects are statistically significant but modest in magnitude. It is worth noting that the power of the first stage regressions are comparable across industries. The variations in the second stage coefficients on Return are unlikely to be driven by the fact that some industries are more prone to mutual fund redemption shocks. Although the analysis in Table 5 is more descriptive than definitive, the cross-industry variations revealed provide additional support to the view that the effects of non-fundamental stock price changes on sales operate through the channel of customer learning from stock prices.

\section{[Insert Table 5 Here.]}

\footnotetext{
${ }^{14}$ The business equipment industry includes some firms producing consumer electronics, such as Apple Inc.
} 


\subsubsection{Dynamic Effects}

In Table 6, I evaluate the dynamics of the effects of non-fundamental stock price fluctuations on sales and online customer interest. For illustration, I use an event study approach. Specifically, I create an event indicator (Event $(t=0))$ for whether MFFlow is above the 90 th percentile in a given period. I also create indicators for the periods before and after an event. In column (1), I regress SaleToAst on the indicator variables, while controlling for the same firm characteristics as in Table 2. The coefficient on Event $(t=0)$ suggests that SaleToAst decreases by 0.29 percentage points $(0.91 \%$ of the average level) during an event quarter, which is statistically significant at the $5 \%$ level. There is no pre-trend in customer interest during the six quarters before a large MFFlow shock, as indicated by the insignificant coefficients on Event $(t=-6)$ to Event $(t=-1)$. This observation is inconsistent with the argument that the poor fundamentals of holdings have caused extreme mutual fund outflows. The absence of a pre-trend suggests that the instrument is plausibly exogenous. The coefficients on Event $(t=1)$ to Event $(t=6)$ suggest that the negative impact of a large MFFlow shock on SaleToAst lasts for up to four quarters but dissipates afterwards. In the top left graph in Figure 4, I plot the coefficients on the event indicators (referred to as "abnormal SaleToAst" in the plot) and the corresponding 95\% confidence intervals. In the top right graph, I compare the abnormal SaleToAst with the quarterly market-adjusted CAAR during the same sample period. The two lines trace out similar patterns: relatively flat pre-trends and comparable durations of 
impact, consistent with the story that customers negatively update about a firm's products when the firm's stock price is temporarily undervalued due to mutual fund redemptions.

In the second column of Table 6 , I repeat the same analysis using the online customer interest measure SVIShop as the dependent variable. The regression coefficients on the event indicators, along with the $95 \%$ confidence intervals, are plotted in the bottom left graph in Figure 4. During the month of a large MFFlow shock $($ Event $(t=0))$, SVIShop decreases by 0.58 units (2.04\% of the average level). There is no significant decline in SVIShop before the event month, an observation that alleviates endogeneity concerns. The effect lasts up to six months after the shock. As shown in the bottom right graph in Figure 4, the recovery time of SVIShop is again similar to that of the monthly market-adjusted $C A A R .^{15}$

[Insert Table 6 and Figure 4 Here.]

\subsubsection{Nearest-Neighbor Matching Analyses}

All results presented so far are estimated using linear regression models. A potential concern is that some observable firm characteristics may affect customer interest and sales nonlinearly. If the 2SLS regressions fail to fully control for these nonlinear effects, the estimated coefficient on Return could be

\footnotetext{
${ }^{15}$ The monthly market-adjusted $C A A R$ is computed in the same way as in Figure 3. However, in this graph, the sample period is from 2004 to 2014, and the treatment variable is determined by the monthly MFFlow measure, as in the online customer interest analysis.
} 
biased. I address this concern by using a nearest-neighbor matching method. Specifically, I define the treatment group as those observations with MFFlow above the 90th percentile in a given period. I then match each observation to a counterfactual that has the most similar ex-ante observable characteristics based on the Mahalanobis distance. To further control for firm fixed effects, I subtract the firm average from each variable before matching.

In Panel A of Table 7, I first run a Logit model to determine the differences in ex-ante characteristics between the treated and the control groups. In the first column, I use the sample of the sales analysis. Because I removed the firm-level average before matching, the results should be interpreted as within-firm variations. As shown, the two groups differ in terms of $\log (A g e)$, $\log (M k t C a p), A d E x p, C O G S, R D E x p$, and Leverage. Therefore, I conduct matching based on these characteristics. The average treatment effect (ATE) is shown in column (1) of Panel B. The result suggests that a MFFlow shock in the top decile reduces the SaleToAst by 0.33 percentage points ( $1.04 \%$ of the average level), an effect statistically significant at the $1 \%$ level. To account for industry trends, I further restrict the match to be within the same FamaFrench 48 industry during the same period. The resulting ATE is slightly smaller in magnitude but still statistically significant at the $1 \%$ level. ${ }^{16}$ For comparison, I also present the estimate obtained from a linear regression of SaleToAst on the treatment variable, while controlling for all characteristics

\footnotetext{
${ }^{16}$ The drawback of matching within the same industry and time period is that it results in larger differences in some of the characteristics after matching.
} 
listed in the first column of Panel A and the industry-time interacted fixed effects. The magnitude of the linear model ATE is comparable to the two matching estimates.

I also repeat the matching algorithm to examine online customer interest. The Logit model in column (2) of Panel A shows that the treatment and control groups are different along four dimensions: SVIFin, $\log (1+$ NewsNum), $\log ($ Age $)$, and Leverage. After matching based on these characteristics, the ATE suggests that a large MFFlow shock on average reduces the online customer interest by 0.75 units (2.62\% of the average level). The effect is statistically significant at the $1 \%$ level. Restricting the match to within the same industry and period gives a similar ATE. Overall, the results in Table 7 suggest that my findings are robust to controlling for nonlinear effects through the nearest-neighbor matching method.

\section{[Insert Table 7 Here.]}

\subsubsection{Additional Robustness Tests}

In this section, I conduct several robustness checks on the main empirical findings that a firm's sales and shopping-related Google search volume both decline when the firm's stock price is negatively impacted by noninformational mutual fund redemptions. In Panel A of Table 8, I evaluate whether the sales results hold under alternative specifications. All regressions

are two-stage least squares (2SLS), in which Return or $Q$ is instrumented 
by MFFlow. Control variables (untabulated in the table for brevity) consist of $\log (A g e), \log (M k t C a p), A d E x p, C O G S, R D E x p, C A P X, H H I I n d$, Leverage, and CashFlow. Return and MFFlow are concurrent to the dependent variable, while controls are lagged by one period. In column (1), I include the firm-quarter of the year interacted fixed effects to absorb potential effects of seasonality. In column (2), I include the industry-time interacted fixed effects to account for the influence of industry trends. The coefficients on the instrumented Return are positive and statistically significant in both columns. The magnitudes of these coefficients are also comparable to the 2SLS estimate shown in Table II (0.0699). Therefore, the sales results are robust to controlling for the effects of seasonality and industry trends. In column (3), I cluster the standard errors at the firm level. The resulting $t$-statistic is greater than that obtained by clustering the standard errors at the industry level. To be conservative, I choose to use the industry-level clustering in the other tests.

In column (4), I use the logarithm of sales, rather than the sales-toassets ratio, as the dependent variable. For ease of interpretation, I multiply $\log ($ Sales $)$ by 100 . The coefficient suggests that, after instrumentation, a decrease of 10 percentage points in a firm's quarterly stock return reduces the firm's quarterly sales by $3.02 \%$. This effect is quantitatively similar to the 2SLS estimate in Table II, which suggests that a decrease of 10 percentage points in the instrumented stock return leads to a decrease of $2.22 \%$ in the sales-to-assets ratio, relative to its average level. In column (5), I consider an alternative measure of stock market valuation - Tobin's $Q$. In my sample, 
the mean and standard deviation of $Q$ are 1.77 and 1.26 , respectively. In the regression, I multiply Q by 100 and instrument it with MFFlow. The result suggests that when the Tobin's $Q$ decreases by one standard deviation, the sales-to-assets ratio declines by 6.11 percentage points, which corresponds to $19.4 \%$ of its average level.

In Panel B of Table 8, I conduct similar robustness tests on the online customer interest results. Control variables (untabulated in the table for brevity) include SVIFin (log $(1+S V I F i n)$ in column (3)), $\log (1+N e w s N u m)$, and all controls used in Panel A. The results in columns (1) - (3) suggest that the negative effects of mutual fund outflow-induced price pressure on a firm's shopping-related Google search volume remain significant statistically and economically after controlling for potential effects of seasonality or industry trends, or clustering the standard errors at the firm level. The results in the last two columns show that these effects are also robust to using $\log (1+S V I S h o p)$ as the dependent variable or using $Q$ to measure the firm's stock market valuation.

[Insert Table 8 Here.]

\subsubsection{Alternative Explanations}

In the next set of tests, I address the concern that my main findings may be driven by financial constraints. Previous studies (e.g., Baker et al. (2003) and Hau and Lai (2013)) find that non-fundamental variations in a firm's stock price can affect corporate decisions through the financial constraint channel. 
In particular, poor stock market performance can hamper a firm's ability to raise capital, thus adversely impacting its real investment. In the context of my paper, financial constraints can curtail firms' spending on marketing and development of new products and consequently reduce sales and online customer interest.

Several empirical observations indicate that this alternative explanation is unlikely to be true. First, I find that the MFFlow shocks have immediate effects (in the contemporaneous period) on sales and online customer interest. This pattern is consistent with the customer learning channel, which can occur instantaneously once customers observe the stock price, while at odds with the financial constraint channel, which must first affect firms' capital budgeting and then customer responses. Second, I directly control for proxies for financial constraints (i.e., the cash flow rate and the leverage ratio) and firm decisions that are affected by financial constraints (i.e., the advertising expense ratio, the $R \& D$ expense ratio, and the capital expenditure rate) in the regressions. Therefore, these variables should be able to absorb the confounding effect, if any such effect exists.

To completely resolve concerns related to financial constraints, I re-run the 2SLS regressions on sales and shopping-related Google search volume after dropping the most financially constrained firms. Table 9 presents the results. In Panel A, I consider the sales-to-assets ratio as the dependent variable. In column (1), I use the index proposed in Kaplan and Zingales (1997) as a proxy for financial constraints and remove all observations with index values in the 
top three deciles. As shown, the coefficient on the instrumented Return remains significantly positive and comparable in magnitude to the full-sample estimate. In column (2), I conduct the same analysis using the financial constraint index proposed in Whited and Wu (2006), instead. The result is again similar to the full-sample estimate.

Another confounding effect related to the financial health of the firm is that large mutual fund flow shocks may coincide with episodes of financial distress. If customers know that the firm is financially distressed from information sources other than the stock price, their demand for the firm's product may decline. However, this is not due to the learning channel proposed in this paper. To alleviate this concern, I drop observations with Altman (1968) z-scores in the bottom three deciles. The result is shown in column (3). Since the coefficient on Return is actually greater than the full-sample estimate, my main finding is unlikely to be driven by financial distress.

In column (4), I address concerns related to recessions. There are two reasons why recessions could potentially affect the interpretation of my main results. First, financial constraints are especially severe for firms during recessionary periods. Second, mutual funds flows and customer demand are both likely to be lower during recessions, posing a challenge to the identification strategy. Since I include time fixed effects in all regressions, the effects of recessions should be mostly removed. To further safeguard against this concern, I exclude all NBER recessionary periods from the sample and re-run the 2SLS regression. The coefficient on Return in column (4) is similar to 
the estimate obtained without excluding the recessionary periods, suggesting that the negative effects of outflow-induced price pressure on sales are not completely explained by recessions. In Panel B, I repeat the same set of tests using SVIShop as the dependent variable and, again, find no evidence suggesting that my main findings are entirely driven by alternative explanations.

[Insert Table 9 Here.]

\subsection{Firm Response to Customer Learning: Product Launch Decisions}

The empirical evidence shown so far has established the mechanism that customers extract information from stock prices to guide their demand for a firm's products. In this section, I assess whether firms respond to this type of learning by adjusting the timing of their product launches. As implied in Corollary 1 of the model, if the manager of the firm is aware of the effect of stock market performance on customer demand, she should avoid announcing new products when the firm's stock return is lower.

\subsubsection{Data on Product Launches}

I obtain press release data from RavenPack News Analytics to measure firms' decisions to launch new products. RavenPack adopts proprietary algorithms to classify firms' press releases into detailed categories, including mergers and acquisitions, pollution, industrial accidents, executive changes, and product releases. I obtain over 100,000 press releases for new products 
and services during the sample period 2004-2014. The press release dataset is merged with other firm characteristics based on historical CUSIP. More details about the selection criteria of the RavenPack sample are given in the appendices. In the regression analysis, I focus on the dummy variable for whether there is any press release on new products and services during a given month, rather than the number of such press releases, because the dummy variable is unlikely to be affected by multiple sources reporting on the same event. The summary statistics of the sample used in the product launch analysis are provided in Panel D of Table 1. On average, the probability of a product launch in a given month is $9.75 \%$.

Compared to traditional measures of investments, such as capital expenditures and R\&D expenses reported in Compustat, examining press releases of new products and services has several advantages. First, the decision to release new products is more dependent on customer demand and thus more suitable for testing the customer learning channel emphasized in the model. Furthermore, analyzing product release decisions while controlling for investments in physical capital and R\&D helps to address alternative concerns related to managerial learning from stock prices and financial constraints.

\subsubsection{Effects of Stock Returns on Product Launch Probability}

I test the implication of Corollary 1 that firms are less likely to launch new products when their stock prices decrease due to non-fundamental shocks using an empirical design similar to that in the customer demand tests. The 
first stage is the same as in equation (3.2). The second stage is as follows:

$$
\operatorname{ProdLauDum}_{i t}=\beta_{r}^{\prime} \widehat{\operatorname{Retur}}_{i t}+\beta_{c}^{\prime} \text { Controls }_{i t-1}+\nu_{i t}^{\prime},
$$

where ProdLauDum is the dummy variable for whether there is a product launch in a given month. Controls are the same as those in Table 2. Based on Corollary 1 , I expect $\beta_{r}^{\prime}$ to be positive and statistically significant.

In column (1) of Table 10, I first examine the OLS regression for comparison. The result suggests that a 10-percentage-point decrease in the firm's stock return is associated with a 0.2-percentage-point decrease in the probability of a product launch. To address the endogeneity of stock returns, I next present estimates from the 2SLS regressions in columns (2) and (3). The results suggest that when the firm's stock return decreases by 10 percentage points, the monthly probability of product launches decreases by 0.89 percentage points, an effect that is statistically significant at the $5 \%$ level. Given the summary statistics in Panel D of Table 1, the effect is $9.09 \%$ of the unconditional monthly launch probability. In the last column, I regress ProdLauDum on the instrument MFFlow directly. The reduced form estimate suggests that when MFFlow increases by one percentage point, the probability of a product launch decreases by 0.083 percentage points. Overall, the results in Table 10 support the prediction of Corollary 1 that in anticipation of depressed customer demand, the manager of the firm is less willing to launch a new product when non-fundamental shocks lower the firm's stock price.

[Insert Table 10 Here.] 


\subsection{Conclusion}

This paper investigates whether and how stock price movements affect customer purchase decisions. Using novel data and an instrumental variable design, I present evidence that sales and online customer interest (as proxied by shopping-related Google searches) decline when a firm's stock return is negatively impacted by non-informational mutual fund redemptions. These effects are stronger when more potential customers are aware of the firm's stock price. Furthermore, firm managers seem to incorporate the negative effect of poor stock market performance on customer demand in their decision making process. Specifically, mutual fund outflow-induced price pressure lowers the probability of product launches. These findings are consistent with a rational expectations model in which customer learning from stock prices leads to feedback effects from the financial market to firms' cash flows and product launch decisions.

This paper is the first to provide direct evidence that customers extract information from stock prices to facilitate their purchase decisions. The real effects of this channel on firms are substantial. Based on my instrumental variable regression estimate, a firm with the median level of total assets (roughly $\$ 250$ million) loses $\$ 1.75$ million of sales in the contemporaneous quarter when its quarterly stock return decreases by 10 percentage points. Furthermore, the loss in sales continues for up to four quarters after the initial shock. From the perspective of a corporate executive, my results suggest that it is important to pay attention to the firm's stock price, since temporary underpricing can 
affect the firm's fundamentals by influencing potential customers' perception of the firm's product quality. Policy makers should also be aware that shocks originated in financial markets can have disruptive effects in the real economy because non-financial decision makers, such as customers, base their decisions on information revealed in stock prices.

While the goal of this paper is to test for the existence of customer learning from stock prices, a few interesting questions related to this mechanism remain unanswered. First, when the stock returns of a firm decline, disappointed customers may switch to close competitors whose stocks have not performed poorly, which results in increases in the competitors' sales. Furthermore, knowing this effect, competitors may also respond by changing their product market strategies. Studying these interactions in the product market can further gauge the economic significance of customer learning from stock prices. Second, the interplay of learning by customers and speculators could potentially explain puzzling observations in financial markets. For instance, Subrahmanyam and Titman (2001) demonstrate theoretically that when the stakeholders of a firm learn from its stock price, the complementarities across these stakeholders can lead to cascades in the firm's stock price, as well as fundamental value. Goldstein et al. (2013) propose a model that explains trading frenzies using feedback effects induced by real decision makers learning from stock prices. Empirical research testing the predictions of these models can help us understand the role of learning in connecting financial markets and the real economy. 


\section{Figure 1: Volatility of the Stock Price}

This figure plots the volatility of the stock price given different parameter values. Specifically, $a$ is the coefficient of risk aversion; $v_{z}$ is the prior variance of the quality shock; $v_{x}$ is the variance of the noise trader shock; $v_{\eta}$ is the variance of the customer's private signal. Price volatility $V[p]$ is defined in equation (2.8).
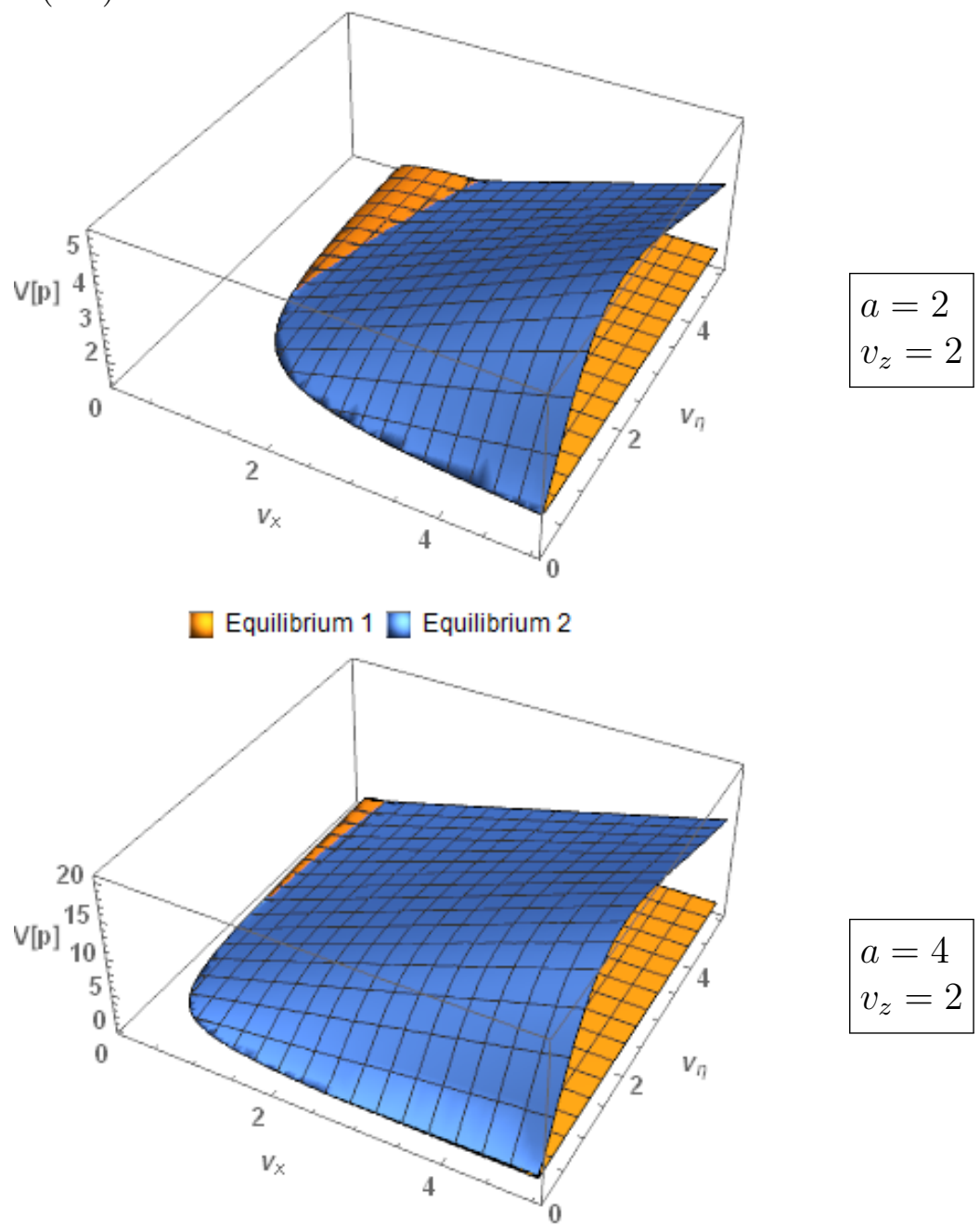

Equilibrium 1 Equilibrium 2 
Figure 1 continued

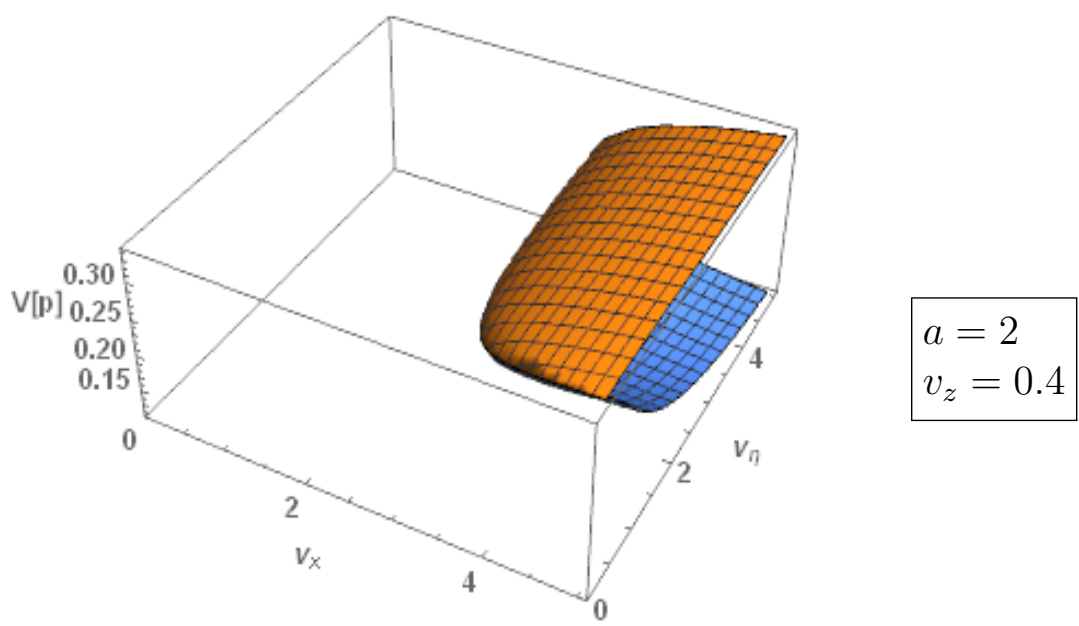

Equilibrium 1 Equilibrium 2

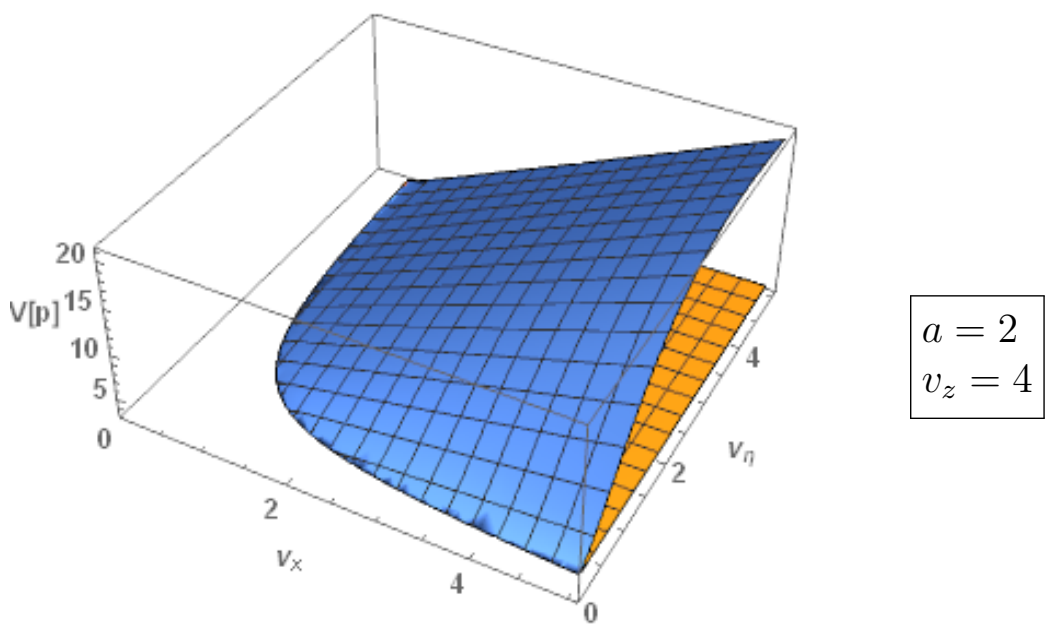

Equilibrium 1 Equilibrium 2 


\section{Figure 2: Online Customer Interest for Apple Inc.}

This figure demonstrates the process used to collect the measure of online customer interest (SVIShop) for Apple Inc. from Google Trends. The top image shows the topics suggested by Google Trends when the term "apple" is used as the search input. The bottom image shows some available categories in Google Trends. The automated script collects the search volume index on the topic labeled as "technology company" in the "shopping" category.

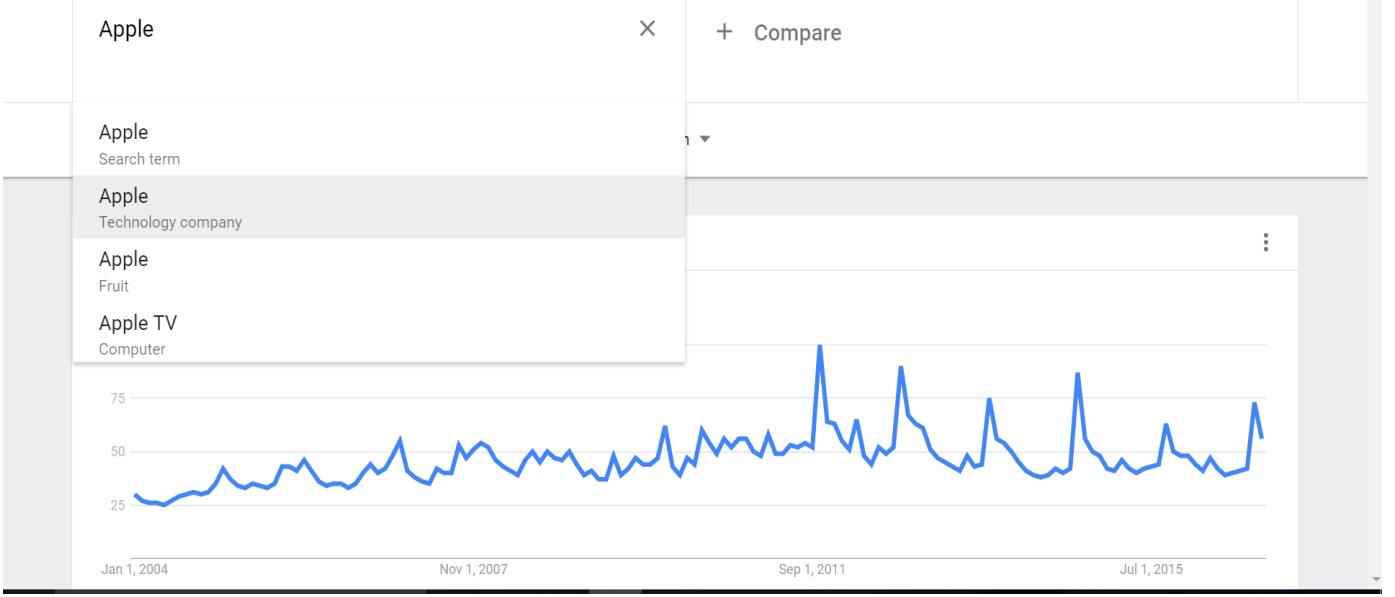

- Apple

Technology company $\quad \vdots+$ Compare

Worldwide $\quad 2004$ - present rch $>$

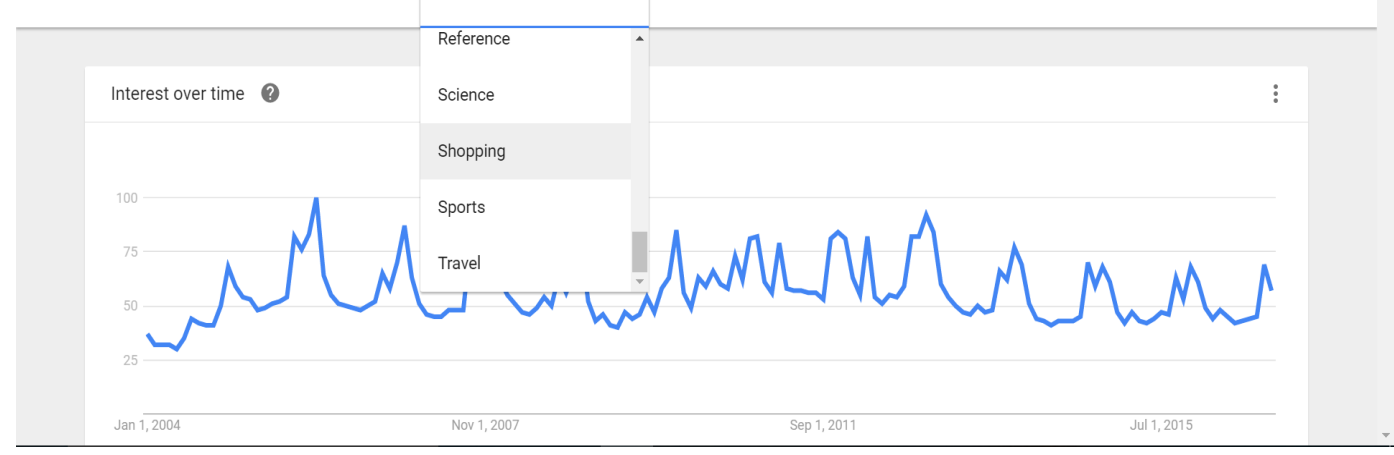

Data source: Google Trends (www.google.com/trends) 


\section{Figure 3: Effects of Large Mutual Fund Redemption Shocks on Stock Returns}

This figure shows the monthly cumulative average abnormal returns (CAAR) around large mutual fund redemption shocks (i.e., MFFlow is above the 90th percentile of the quarter) and the corresponding quarterly MFFlow. To avoid discretionary trading by the fund managers, MFFlow is computed by assuming that the distress funds sell their existing holdings proportionally to ex-ante portfolio weights. More details regarding the construction of MFFlow is provided in Section 3.13.1.2. Abnormal returns are computed using three different benchmarks: the CRSP equal-weighted index (red), the Fama-French equal-weighted 48 industry portfolios (blue), and the characteristic-matched portfolios proposed in Daniel et al. (1997) (green). The sample period is 1980-2014.
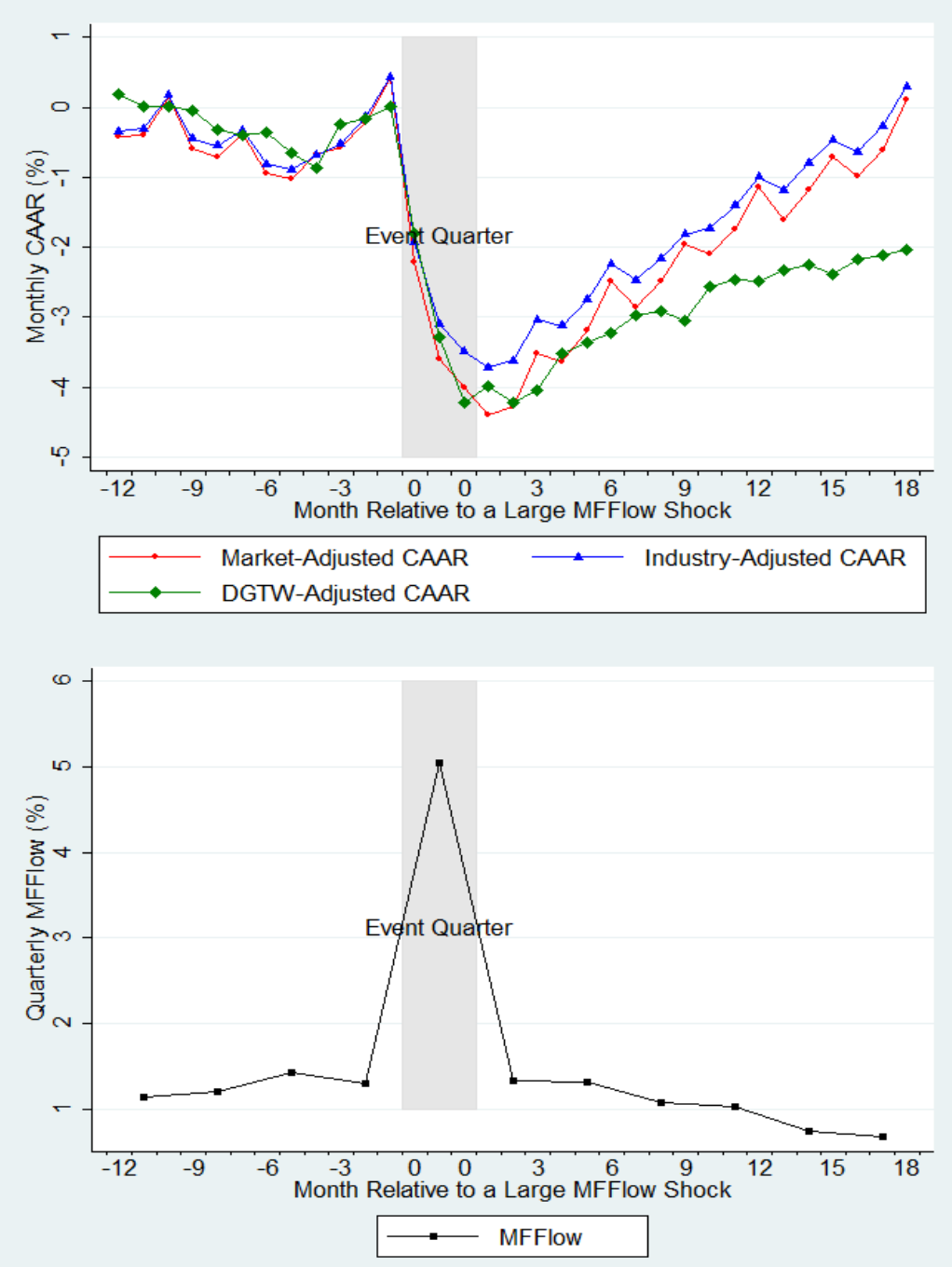


\section{Figure 4: Effects of Large Mutual Fund Redemption Shocks on Sales and Online Customer Interest}

This figure plots the abnormal sales-to-assets ratios (SaleToAst) and shopping-related online search volume indices (SVIShop) around large mutual fund redemption shocks (i.e., MFFlow is above the 90th percentile of the period). Abnormal SaleToAst and SVIShop are the coefficients on the event indicators estimated using regressions in Table 6 . The two graphs on the left show the abnormal SaleToAst and SVIShop, along with their respective 95\% confidence intervals. The two graphs on the right contrast the abnormal SaleToAst and SVIShop with the corresponding market-adjusted cumulative average abnormal stock returns (CAAR) during the same periods. The sample period for the sales analysis is 19802014, while that for the online search volume analysis is 2004-2014. The CAAR plots appear to be different mainly because of the two different sample periods.
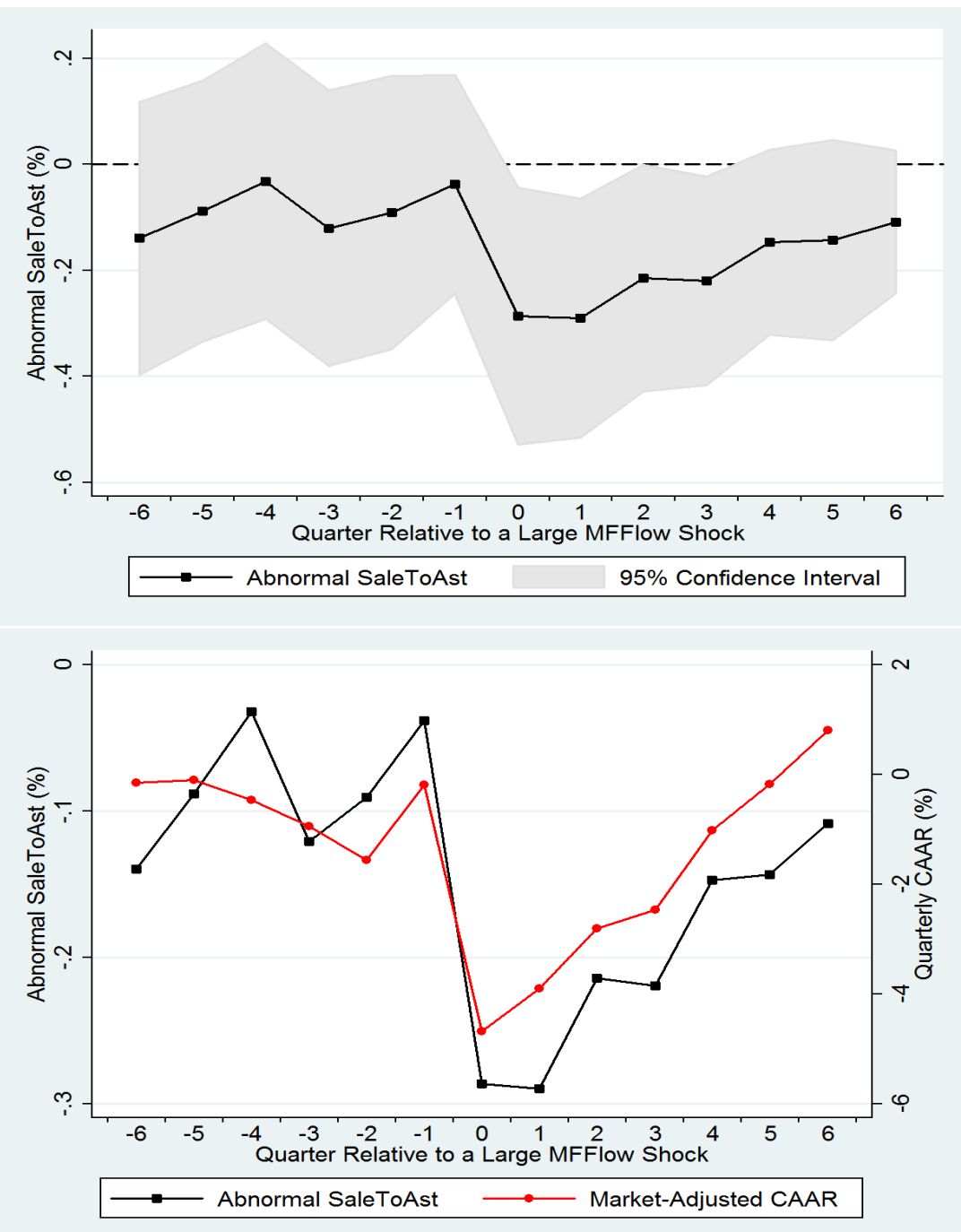
Figure 4 continued

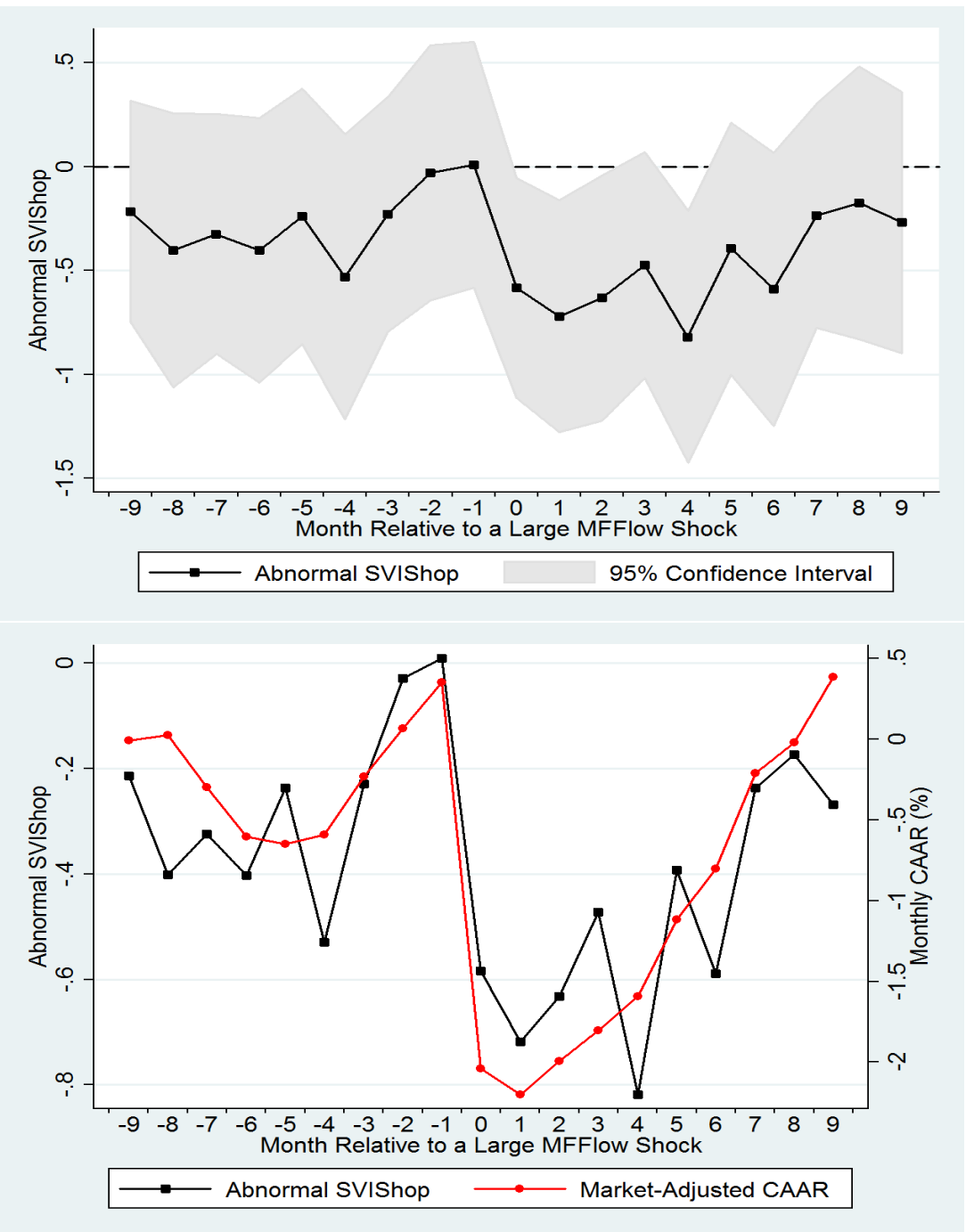




\section{Table 1: Variable Definitions and Summary Statistics}

\begin{tabular}{|c|c|}
\hline & Panel A. Variable Definitions \\
\hline \multicolumn{2}{|c|}{ Variables from Compustat: } \\
\hline SaleToAst & $\begin{array}{l}\text { sales-to-assets ratio (i.e., asset turnover) }=\text { sales/lagged } \\
\text { book assets }\end{array}$ \\
\hline AdExp & $\begin{array}{l}\text { advertising expense ratio }=\text { advertising expenses/sales; zero } \\
\text { if missing }\end{array}$ \\
\hline COGS & cost of goods sold ratio $=$ cost of goods sold $/$ sales \\
\hline RDExp & $\mathrm{R} \& \mathrm{D}$ expense ratio $=\mathrm{R} \& \mathrm{D}$ expenses $/$ sales; zero if missing \\
\hline CAPX & $\begin{array}{l}\text { capital expenditure rate }=\text { capital expenditures/lagged book } \\
\text { assets }\end{array}$ \\
\hline HHIInd & $\begin{array}{l}\text { industry concentration }=\text { sales Herfindahl index of the } \\
\text { Fama-French } 48 \text { industry }\end{array}$ \\
\hline Leverage & $\begin{array}{l}\text { leverage ratio }=(\text { long-term debt }+ \text { debt in current liabilities } \\
\text { - cash and short-term investments }) / \text { book assets }\end{array}$ \\
\hline CashFlow & $\begin{array}{l}\text { cash flow rate }=(\text { income before extraordinary items }+ \text { de- } \\
\text { preciation and amortization }) / \text { lagged assets }\end{array}$ \\
\hline \multicolumn{2}{|c|}{ Variables from CRSP: } \\
\hline Return & $\begin{array}{l}\text { stock return (monthly or quarterly, depending on the spec- } \\
\text { ifications) }\end{array}$ \\
\hline Age & $\begin{array}{l}\text { age of the firm }=\text { number of years since first appearing in } \\
\text { CRSP }\end{array}$ \\
\hline MktCap & $\begin{array}{l}\text { market capitalization }=\text { price } \times \text { total number of shares out- } \\
\text { standing }\end{array}$ \\
\hline \multicolumn{2}{|c|}{ Variables from Google Trends: } \\
\hline SVIShop & $\begin{array}{l}\text { Google search volume index on the Google topic of a given } \\
\text { company in the category "shopping" }\end{array}$ \\
\hline SVIFin & $\begin{array}{l}\text { Google search volume index on the Google topic of a given } \\
\text { company in the category "finance" }\end{array}$ \\
\hline SVITic & $\begin{array}{l}\text { Google search volume index on the stock ticker of a given } \\
\text { company }\end{array}$ \\
\hline \multicolumn{2}{|c|}{ Variables from RavenPack News Analytics: } \\
\hline NewsNum & number of news reports \\
\hline ProdLauDum & $\begin{array}{l}\text { dummy variable for whether there is a press release on new } \\
\text { products or services }\end{array}$ \\
\hline ProdLauNum & number of press releases on new products or services \\
\hline
\end{tabular}


Table 1 continued

\begin{tabular}{|c|c|c|c|c|c|c|c|}
\hline \multicolumn{8}{|c|}{$\begin{array}{l}\text { Panel B. Summary Statistics for Sales Regressions } \\
\text { (Quarterly Data; Sample Period: 1980-2014) }\end{array}$} \\
\hline & Mean & SD & P10 & P25 & $\mathrm{P} 50$ & $\mathrm{P} 75$ & $\mathrm{P} 90$ \\
\hline SaleToAst (\%) & 31.52 & 21.29 & 8.984 & 16.97 & 27.56 & 40.42 & 58.06 \\
\hline Age (years) & 15.96 & 15.73 & 1.750 & 4.500 & 11.25 & 21.75 & 36.25 \\
\hline MktCap (million \$) & 2,351 & 12,790 & 26.07 & 64.99 & 227.3 & 919.0 & 3,428 \\
\hline $\operatorname{AdExp}(\%)$ & 1.176 & 2.866 & 0 & 0 & 0 & 1.018 & 3.570 \\
\hline COGS (\%) & 74.24 & 78.22 & 32.98 & 50.32 & 66.49 & 78.99 & 89.22 \\
\hline RDExp (\%) & 12.56 & 57.17 & 0 & 0 & 0 & 4.289 & 17.31 \\
\hline CAPX (\%) & 1.628 & 2.057 & 0.0841 & 0.396 & 0.963 & 2.010 & 3.816 \\
\hline HHIInd & 0.0874 & 0.0769 & 0.0363 & 0.0436 & 0.0613 & 0.0984 & 0.173 \\
\hline Leverage (\%) & 3.395 & 33.06 & -44.60 & -16.85 & 8.927 & 27.48 & 41.35 \\
\hline CashFlow (\%) & 1.730 & 3.901 & -1.954 & 0.960 & 2.277 & 3.605 & 5.122 \\
\hline Return (quarterly \%) & 3.255 & 25.98 & -26.53 & -11.76 & 1.653 & 15.75 & 33.25 \\
\hline MFFlow (quarterly \%) & 0.336 & 0.871 & 0 & 0 & 0.0289 & 0.256 & 0.839 \\
\hline No. of Firms & 10,017 & & & & & & \\
\hline No. of Obs. & 311,368 & & & & & & \\
\hline
\end{tabular}

Panel C. Summary Statistics for Online Customer Interest Regressions (Monthly Data; Sample Period: 2004-2014)

\begin{tabular}{lccccccc}
\hline & Mean & SD & P10 & P25 & P50 & P75 & P90 \\
\hline SVIShop & 28.66 & 23.11 & 3 & 10 & 23 & 43 & 62 \\
SVIFin & 23.36 & 22.78 & 0 & 5 & 17 & 36 & 57 \\
SVITic & 35.33 & 25.31 & 0 & 14 & 35 & 55 & 70 \\
NewsNum & 19.46 & 33.27 & 1 & 5 & 11 & 22 & 41 \\
Return (monthly \%) & 1.108 & 13.36 & -12.86 & -5.501 & 0.845 & 7.126 & 14.69 \\
MFFlow (monthly \%) & 0.796 & 4.713 & 0.0127 & 0.0975 & 0.306 & 0.788 & 1.761 \\
No. of Firms & & & & & & & \\
No. of Obs. & 2,133 & & & & & & \\
\hline
\end{tabular}

Panel D. Summary Statistics for Product Launch Regressions (Monthly Data; Sample Period: 2004-2014)

\begin{tabular}{lccccccc}
\hline & Mean & SD & P10 & P25 & P50 & P75 & P90 \\
\hline ProdLauDum & 0.0975 & 0.297 & 0 & 0 & 0 & 0 & 0 \\
ProdLauNum & 0.199 & 0.784 & 0 & 0 & 0 & 0 & 0 \\
& & & & & & & \\
No. of Firms & 4,318 & & & & & & \\
No. of Obs. & 299,521 & & & & & & \\
\hline
\end{tabular}




\section{Table 2: Effects of Stock Returns on Sales}

This table examines whether the sales-to-assets ratio decreases when the stock return of the firm is lower. The unit of observation is firm-quarter. I present the $t$-statistics in the parentheses. Standard errors are clustered by industry. ***, ${ }^{* *}$, and ${ }^{*}$ denote statistical significance at the $1 \%, 5 \%$, and $10 \%$ levels, respectively.

\begin{tabular}{|c|c|c|c|c|}
\hline & \multirow{3}{*}{$\frac{(1)}{\text { OLS }}$} & $(2)$ & $(3)$ & \multirow{3}{*}{$\frac{(4)}{\text { Reduced Form }}$} \\
\hline & & \multicolumn{2}{|c|}{2 SLS } & \\
\hline & & 1st Stage & 2nd Stage & \\
\hline Dependent Variable & SaleToAst & Return & SaleToAst & SaleToAst \\
\hline Return & $\begin{array}{c}0.0405^{* * *} \\
(13.88)\end{array}$ & & $\begin{array}{c}0.0699^{* * *} \\
(4.833)\end{array}$ & \\
\hline MFFlow & & $\begin{array}{c}-2.296^{* * *} \\
(-15.13)\end{array}$ & & $\begin{array}{c}-0.161^{* * *} \\
(-4.466)\end{array}$ \\
\hline $\log ($ Age $)$ & $\begin{array}{c}0.172 \\
(0.387)\end{array}$ & $\begin{array}{c}0.602^{* *} \\
(2.428)\end{array}$ & $\begin{array}{c}0.157 \\
(0.355)\end{array}$ & $\begin{array}{c}0.199 \\
(0.447)\end{array}$ \\
\hline $\log (\mathrm{MktCap})$ & $\begin{array}{c}-0.818^{* * *} \\
(-4.229)\end{array}$ & $\begin{array}{c}-7.360^{* * *} \\
(-20.82)\end{array}$ & $\begin{array}{c}-0.601^{* * *} \\
(-2.819)\end{array}$ & $\begin{array}{c}-1.115^{* * *} \\
(-5.404)\end{array}$ \\
\hline AdExp & $\begin{array}{l}-0.0401 \\
(-0.808)\end{array}$ & $\begin{array}{c}-0.0620^{*} \\
(-1.831)\end{array}$ & $\begin{array}{l}-0.0383 \\
(-0.772)\end{array}$ & $\begin{array}{l}-0.0426 \\
(-0.857)\end{array}$ \\
\hline COGS & $\begin{array}{c}0.00684 \\
(1.325)\end{array}$ & $\begin{array}{c}-0.00884^{* * *} \\
(-5.444)\end{array}$ & $\begin{array}{c}0.00711 \\
(1.381)\end{array}$ & $\begin{array}{c}0.00649 \\
(1.252)\end{array}$ \\
\hline RDExp & $\begin{array}{c}-0.0204^{* *} \\
(-2.460)\end{array}$ & $\begin{array}{c}0.0172^{* * * *} \\
(5.871)\end{array}$ & $\begin{array}{c}-0.0209^{* *} \\
(-2.527)\end{array}$ & $\begin{array}{c}-0.0197^{* *} \\
(-2.369)\end{array}$ \\
\hline CAPX & $\begin{array}{c}0.383^{* * *} \\
(5.024)\end{array}$ & $\begin{array}{c}-0.157^{* * *} \\
(-3.324)\end{array}$ & $\begin{array}{c}0.388^{* * *} \\
(5.006)\end{array}$ & $\begin{array}{c}0.377^{* * *} \\
(5.026)\end{array}$ \\
\hline HHIInd & $\begin{array}{c}-1.018 \\
(-0.863)\end{array}$ & $\begin{array}{c}-0.114 \\
(-0.0635)\end{array}$ & $\begin{array}{c}-1.018 \\
(-0.874)\end{array}$ & $\begin{array}{c}-1.026 \\
(-0.852)\end{array}$ \\
\hline Leverage & $\begin{array}{c}0.00270 \\
(0.287)\end{array}$ & $\begin{array}{c}-0.0516^{\text {*** }} \\
(-6.849)\end{array}$ & $\begin{array}{c}0.00419 \\
(0.435)\end{array}$ & $\begin{array}{c}0.000581 \\
(0.0611)\end{array}$ \\
\hline CashFlow & $\begin{array}{c}0.564^{* * *} \\
(10.34)\end{array}$ & $\begin{array}{c}0.927^{* * *} \\
(17.69)\end{array}$ & $\begin{array}{c}0.537^{* * *} \\
(9.948)\end{array}$ & $\begin{array}{c}0.602^{* * *} \\
(10.80)\end{array}$ \\
\hline Observations & 311,368 & 311,368 & 311,368 & 311,368 \\
\hline R-squared & 0.823 & 0.274 & 0.822 & 0.821 \\
\hline Firm FE & YES & YES & YES & YES \\
\hline Time FE & YES & YES & YES & YES \\
\hline
\end{tabular}




\section{Table 3: Effects of Stock Returns on Online Customer Interest}

This table examines whether the online customer interest, as measured by SVIShop, decreases when the stock return of the firm is lower. The unit of observation is firm-month. I present the $t$-statistics in the parentheses. Standard errors are clustered by industry. ${ }^{* * *},{ }^{* *}$, and $*$ denote statistical significance at the $1 \%, 5 \%$, and $10 \%$ levels, respectively.

\begin{tabular}{|c|c|c|c|c|}
\hline & \multirow{3}{*}{$\begin{array}{c}(1) \\
\text { OLS }\end{array}$} & $(2)$ & (3) & $(4)$ \\
\hline & & \multicolumn{2}{|c|}{2 SLS } & \multirow{2}{*}{ Reduced Form } \\
\hline & & 1st Stage & 2nd Stage & \\
\hline Dependent Variable & SVIShop & Return & SVIShop & SVIShop \\
\hline Return & $\begin{array}{c}0.0374^{* * *} \\
(5.660)\end{array}$ & & $\begin{array}{c}0.151^{* *} \\
(2.175)\end{array}$ & \\
\hline MFFlow & & $\begin{array}{c}-0.983^{* * *} \\
(-20.42)\end{array}$ & & $\begin{array}{c}-0.148^{* *} \\
(-2.126)\end{array}$ \\
\hline SVIFin & $\begin{array}{c}0.119^{* * *} \\
(6.993)\end{array}$ & $\begin{array}{c}0.000645 \\
(0.403)\end{array}$ & $\begin{array}{c}0.120^{* * *} \\
(6.994)\end{array}$ & $\begin{array}{c}0.120^{* * *} \\
(7.004)\end{array}$ \\
\hline $\log (1+$ NewsNum $)$ & $\begin{array}{c}0.300^{* * *} \\
(3.369)\end{array}$ & $\begin{array}{c}0.541^{* * *} \\
(11.11)\end{array}$ & $\begin{array}{c}0.250^{* *} \\
(2.209)\end{array}$ & $\begin{array}{c}0.331^{* * *} \\
(3.541)\end{array}$ \\
\hline $\log ($ Age $)$ & $\begin{array}{c}4.538^{* * *} \\
(5.368)\end{array}$ & $\begin{array}{c}0.445 \\
(1.196)\end{array}$ & $\begin{array}{c}4.468^{* * *} \\
(5.233)\end{array}$ & $\begin{array}{c}4.540^{* * *} \\
(5.362)\end{array}$ \\
\hline $\log ($ MktCap) & $\begin{array}{c}3.433^{* * *} \\
(8.648)\end{array}$ & $\begin{array}{c}-3.687^{* * *} \\
(-26.02)\end{array}$ & $\begin{array}{c}3.871^{* * *} \\
(8.534)\end{array}$ & $\begin{array}{c}3.309^{* * *} \\
(8.143)\end{array}$ \\
\hline AdExp & $\begin{array}{c}0.249^{* * *} \\
(2.726)\end{array}$ & $\begin{array}{c}0.00444 \\
(0.183)\end{array}$ & $\begin{array}{c}0.250^{* *} \\
(2.700)\end{array}$ & $\begin{array}{c}0.250^{* * *} \\
(2.743)\end{array}$ \\
\hline COGS & $\begin{array}{c}0.0118^{* * *} \\
(3.313)\end{array}$ & $\begin{array}{c}-0.00349^{*} \\
(-1.720)\end{array}$ & $\begin{array}{c}0.0123^{* * *} \\
(3.439)\end{array}$ & $\begin{array}{c}0.0118^{* * *} \\
(3.297)\end{array}$ \\
\hline RDExp & $\begin{array}{c}-0.0120^{* * *} \\
(-3.260)\end{array}$ & $\begin{array}{c}0.00156 \\
(0.610)\end{array}$ & $\begin{array}{c}-0.0122^{* * *} \\
(-3.136)\end{array}$ & $\begin{array}{c}-0.0121^{* * *} \\
(-3.261)\end{array}$ \\
\hline CAPX & $\begin{array}{c}-0.176 \\
(-1.021)\end{array}$ & $\begin{array}{c}-0.175^{* * *} \\
(-4.141)\end{array}$ & $\begin{array}{c}-0.152 \\
(-0.870)\end{array}$ & $\begin{array}{c}-0.183 \\
(-1.067)\end{array}$ \\
\hline HHIInd & $\begin{array}{c}12.77 \\
(0.801)\end{array}$ & $\begin{array}{c}1.271 \\
(0.635)\end{array}$ & $\begin{array}{c}12.53 \\
(0.783)\end{array}$ & $\begin{array}{c}12.70 \\
(0.797)\end{array}$ \\
\hline Leverage & $\begin{array}{c}0.0323^{*} \\
(1.974)\end{array}$ & $\begin{array}{c}-0.0201^{* * *} \\
(-4.677)\end{array}$ & $\begin{array}{c}0.0353^{* *} \\
(2.150)\end{array}$ & $\begin{array}{c}0.0321^{*} \\
(1.971)\end{array}$ \\
\hline CashFlow & $\begin{array}{l}-0.0451 \\
(-1.089)\end{array}$ & $\begin{array}{c}0.275^{* * *} \\
(15.36)\end{array}$ & $\begin{array}{c}-0.0824^{*} \\
(-1.737)\end{array}$ & $\begin{array}{l}-0.0447 \\
(-1.177)\end{array}$ \\
\hline Observations & 167,895 & 167,895 & 167,895 & 167,895 \\
\hline R-squared & 0.508 & 0.252 & 0.503 & 0.507 \\
\hline Firm FE & YES & YES & YES & YES \\
\hline Time FE & YES & YES & YES & YES \\
\hline
\end{tabular}




\section{Table 4: Heterogeneous Effects across Online Financial Interest}

This table examines the heterogeneity in the effects of stock returns on sales (columns (1) and (2)) and online customer interest (columns (3) and (4)) across different levels of online financial interest. The unit of observation is firm-quarter in the first two columns and firm-month in the last two. The regressions are estimated using the 2SLS method, in which Return and Return $\times$ High $X$ are instrumented by MFFlow and MFFlow $\times$ High X, where the variable High $X$ denotes an indicator for whether characteristic $X$ is above the firm-level median. Other control variables (untabulated in the table for brevity) are the same as those in Table 2 in the first two columns, and Table 3 (except for SVIFin) in the last two columns. There are fewer observations in the first two columns compared with those in Table 2 because SVIFin and SVITic are only available since 2004 for a subsample of firms. I present the $t$-statistics in the parentheses. Standard errors are clustered by industry. $* * *, * *$, and $*$ denote statistical significance at the $1 \%, 5 \%$, and $10 \%$ levels, respectively.

\begin{tabular}{lcc|cc}
\hline & $(1)$ & $(2)$ & $(3)$ & $(4)$ \\
\hline Financial Interest & SVIFin & SVITic & SVIFin & SVITic \\
Proxy & & & & \\
\hline & & & & \\
Dependent Variable & SaleToAst & SaleToAst & SVIShop & SVIShop \\
\hline Return & $0.0540^{* *}$ & $0.0705^{* *}$ & 0.0661 & $0.137^{* * *}$ \\
& $(2.078)$ & $(2.405)$ & $(0.762)$ & $(2.664)$ \\
Return $\times$ High SVIFin & $0.0601^{* *}$ & & $0.277^{* * *}$ & \\
& $(2.302)$ & & $(2.903)$ & \\
High SVIFin & -0.0747 & & $3.106^{* * *}$ & \\
& $(-0.661)$ & & $(6.370)$ & \\
Return $\times$ High SVITic & & $0.0437^{*}$ & & $0.148^{* *}$ \\
& & $(1.658)$ & & $(2.262)$ \\
High SVITic & & $0.209^{*}$ & & $0.726^{* * *}$ \\
& & $(1.960)$ & & $(7.305)$ \\
Observations & & & \\
R-squared & 60,013 & 60,013 & 167,895 & 167,895 \\
Controls & 0.882 & 0.883 & 0.495 & 0.492 \\
Firm FE & YES & YES & YES & YES \\
Time FE & YES & YES & YES & YES \\
\hline
\end{tabular}




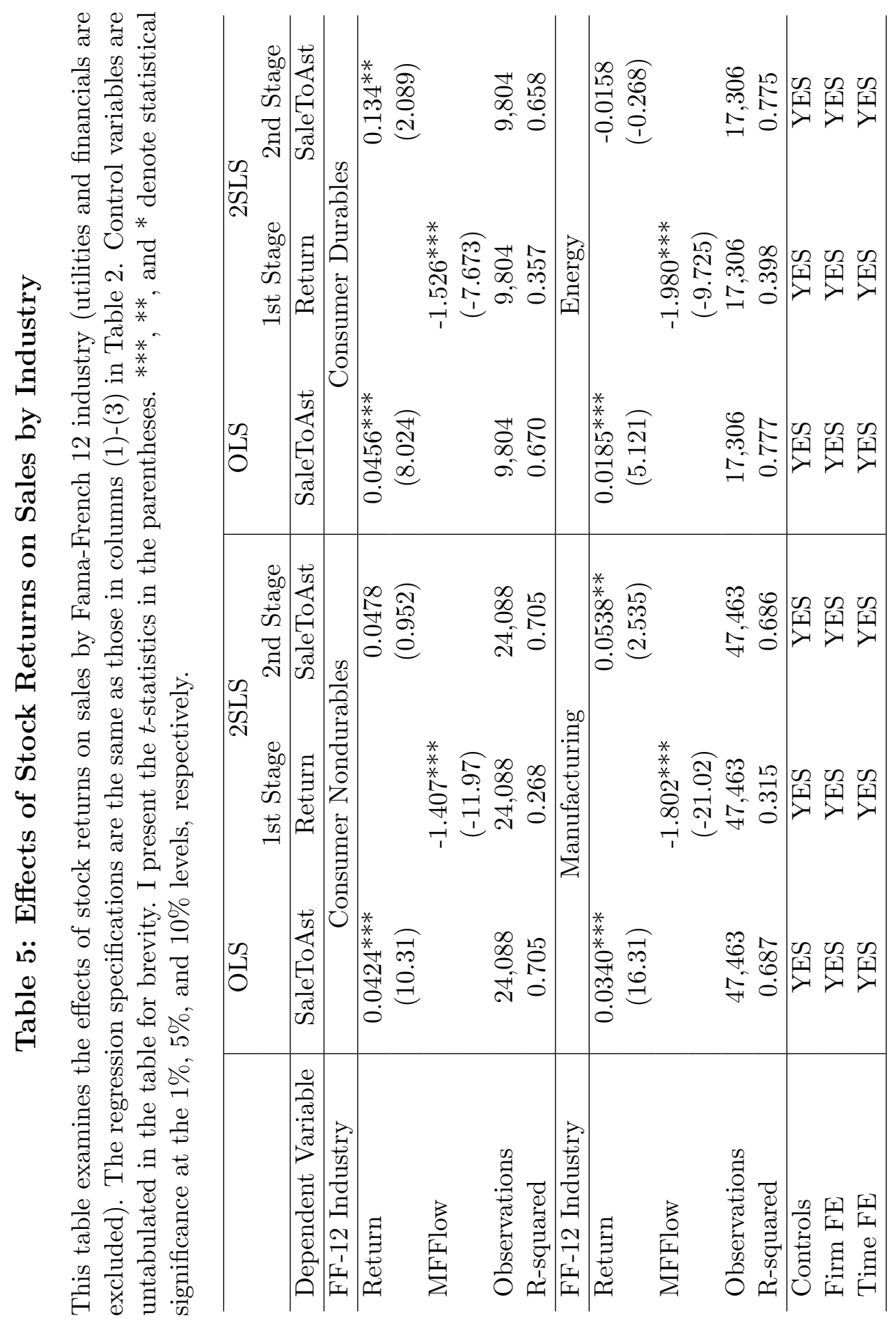




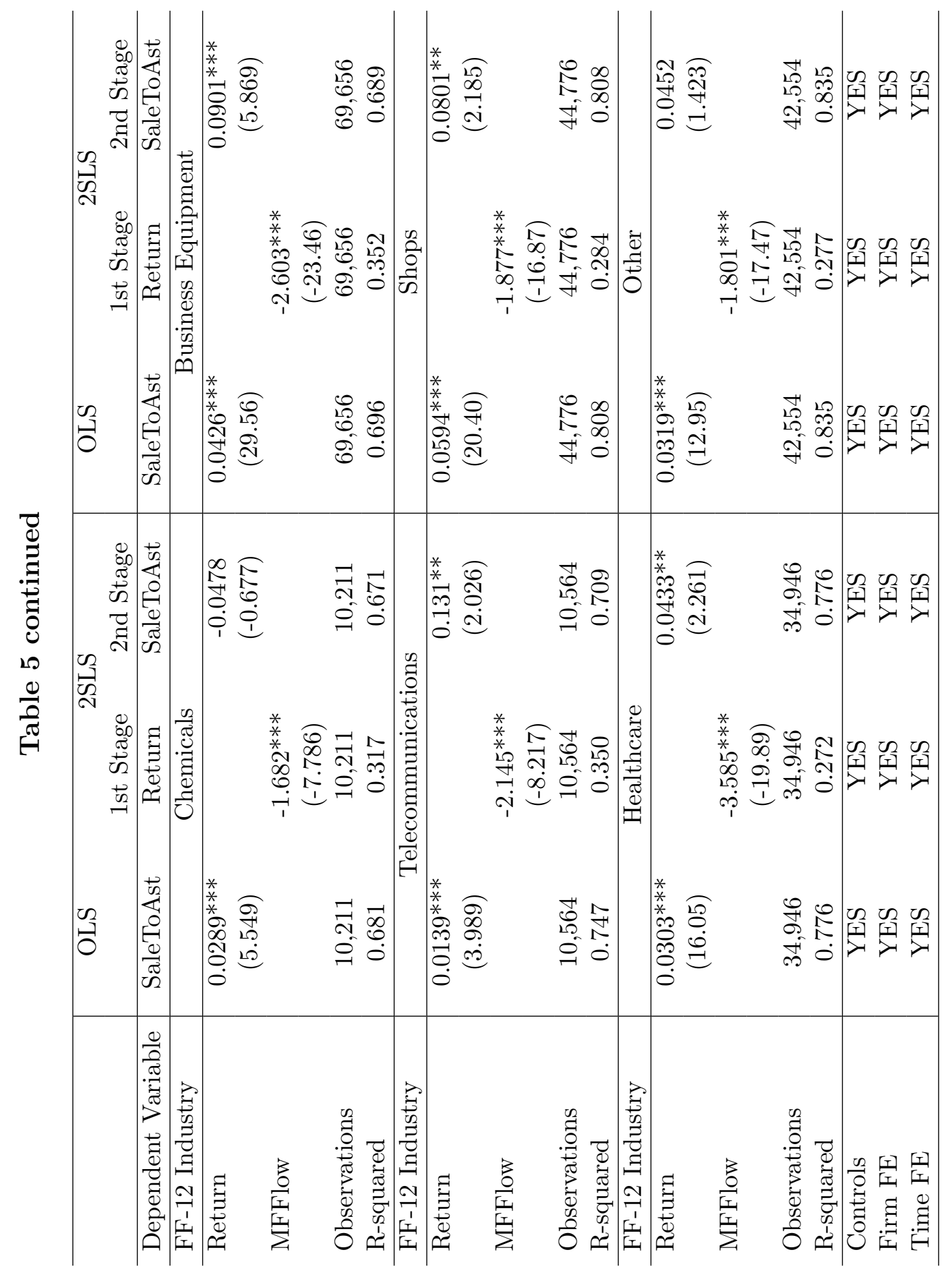




\section{Table 6: Dynamic Effects of Large Mutual Fund Redemption Shocks on Sales and Online Customer Interest}

This table examines the effects of large mutual fund redemption shocks on sales and online customer interest. Event $(t=0)$ is an indicator variable for whether MFFlow is above the 90th percentile of the period. Indicator variables are also created for the periods before and after an event (Event $(t=-9)$-Event $(t=9))$. The unit of observation is firm-quarter in the first column and firm-month in the second. Control variables (untabulated in the table for brevity) are the same as those in Table 2 in column (1), and Table 3 in column (2). The numbers of observations are fewer because regressions in this table require non-missing values for lead and lag terms of MFFlow. I present the $t$-statistics in the parentheses. Standard errors are clustered by industry. $* * *, * *$, and $*$ denote statistical significance at the $1 \%, 5 \%$, and $10 \%$ levels, respectively.

\begin{tabular}{|c|c|c|}
\hline & $(1)$ & $(2)$ \\
\hline & Sales (Quarterly) & Online Customer Interest (Monthly) \\
\hline Dependent Variable & SaleToAst & SVIShop \\
\hline $\operatorname{Event}(\mathrm{t}=-9)$ & & $\begin{array}{l}-0.214 \\
(-0.796)\end{array}$ \\
\hline Event $(\mathrm{t}=-8)$ & & $\begin{array}{l}-0.402 \\
(-1.201)\end{array}$ \\
\hline Event $(\mathrm{t}=-7)$ & & $\begin{array}{l}-0.324 \\
(-1.107)\end{array}$ \\
\hline Event $(\mathrm{t}=-6)$ & $\begin{array}{l}-0.139 \\
(-1.095)\end{array}$ & $\begin{array}{c}-0.403 \\
(-1.248)\end{array}$ \\
\hline Event $(\mathrm{t}=-5)$ & $\begin{array}{l}-0.0884 \\
(-0.725)\end{array}$ & $\begin{array}{l}-0.237 \\
(-0.760)\end{array}$ \\
\hline $\operatorname{Event}(t=-4)$ & $\begin{array}{l}-0.0320 \\
(-0.248)\end{array}$ & $\begin{array}{l}-0.529 \\
(-1.523)\end{array}$ \\
\hline $\operatorname{Event}(\mathrm{t}=-3)$ & $\begin{array}{l}-0.121 \\
(-0.938)\end{array}$ & $\begin{array}{c}-0.229 \\
(-0.800)\end{array}$ \\
\hline Event $(\mathrm{t}=-2)$ & $\begin{array}{l}-0.0907 \\
(-0.711)\end{array}$ & $\begin{array}{c}-0.0286 \\
(-0.0919)\end{array}$ \\
\hline $\operatorname{Event}(t=-1)$ & $\begin{array}{l}-0.0381 \\
(-0.372)\end{array}$ & $\begin{array}{l}0.00861 \\
(0.0287)\end{array}$ \\
\hline $\operatorname{Event}(\mathrm{t}=0)$ & $\begin{array}{c}-0.286 * * \\
(-2.386)\end{array}$ & $\begin{array}{c}-0.584^{* *} \\
(-2.178)\end{array}$ \\
\hline $\operatorname{Event}(t=1)$ & $\begin{array}{c}-0.290 * * \\
(-2.600)\end{array}$ & $\begin{array}{r}-0.719^{* *} \\
(-2.546)\end{array}$ \\
\hline $\operatorname{Event}(\mathrm{t}=2)$ & $\begin{array}{c}-0.214^{* *} \\
(-2.026)\end{array}$ & $\begin{array}{c}-0.632^{* *} \\
(-2.113)\end{array}$ \\
\hline Event $(\mathrm{t}=3)$ & $\begin{array}{c}-0.219 * * \\
(-2.255)\end{array}$ & $\begin{array}{l}-0.473^{*} \\
(-1.714)\end{array}$ \\
\hline $\operatorname{Event}(\mathrm{t}=4)$ & $\begin{array}{l}-0.147^{*} \\
(-1.706)\end{array}$ & $\begin{array}{c}-0.819^{* * *} \\
(-2.664)\end{array}$ \\
\hline Event $(\mathrm{t}=5)$ & $\begin{array}{l}-0.143 \\
(-1.529)\end{array}$ & $\begin{array}{l}-0.393 \\
(-1.278)\end{array}$ \\
\hline $\operatorname{Event}(\mathrm{t}=6)$ & $\begin{array}{l}-0.109 \\
(-1.627)\end{array}$ & $\begin{array}{l}-0.590^{*} \\
(-1.765)\end{array}$ \\
\hline $\operatorname{Event}(\mathrm{t}=7)$ & & $\begin{array}{l}-0.236 \\
(-0.863)\end{array}$ \\
\hline Event $(\mathrm{t}=8)$ & & $\begin{array}{c}-0.174 \\
(-0.523)\end{array}$ \\
\hline Event $(\mathrm{t}=9)$ & & $\begin{array}{l}-0.268 \\
(-0.843)\end{array}$ \\
\hline Observations & 281,357 & 154,552 \\
\hline R-squared & 0.827 & 0.493 \\
\hline Controls & YES & YES \\
\hline Firm FE & YES & YES \\
\hline Time FE & YES & YES \\
\hline
\end{tabular}




\section{Table 7: Nearest-Neighbor Matching Analyses}

This table shows the results from the nearest-neighbor matching analyses. The treatment group consists of observations with MFFlow above the 90th percentile of the period. In Panel A, I first examine a Logit model to determine the differences in observable ex-ante characteristics between the treated and control groups. The characteristics with statistically significant coefficients are used as matching criteria. In the first row of Panel B, I report the average treatment effect (ATE) obtained from matching each observation with a counterfactual that has the most similar characteristics based on the Mahalanobis distance. In the second row, I further require the match to be within the same industry and period. In the third row, I report the ATE obtained from a linear regression of SaleToAst or SVIShop on the treatment variable, the firm characteristics specified in Panel A, and the industry-time interacted fixed effects. To account for firm fixed effects, I remove the firm average from each variable before the matching analysis. ***, **, and * denote statistical significance at the $1 \%, 5 \%$, and $10 \%$ levels, respectively.

\begin{tabular}{|c|c|c|}
\hline \multicolumn{3}{|c|}{ Panel A. Logit Model to Determine Differences in Observable Characteristics } \\
\hline \multicolumn{3}{|c|}{ Dependent variable: whether the demeaned MFFlow is above the 90th percentile of the period } \\
\hline Demeaned characteristics & Sales Sample & Online Customer Interest Sample \\
\hline SVIFin & & $\begin{array}{c}-0.00237^{* * *} \\
(-3.567)\end{array}$ \\
\hline $\log (1+$ NewsNum $)$ & & $\begin{array}{c}-0.215^{* * *} \\
(-16.19)\end{array}$ \\
\hline $\log ($ Age $)$ & $\begin{array}{c}0.171^{* * *} \\
(10.13)\end{array}$ & $\begin{array}{c}0.365^{* * *} \\
(7.686)\end{array}$ \\
\hline $\log (\mathrm{MktCap})$ & $\begin{array}{c}0.0755^{* * *} \\
(7.930)\end{array}$ & $\begin{array}{l}-0.0293 \\
(-1.281)\end{array}$ \\
\hline AdExp & $\begin{array}{c}-0.0101^{* *} \\
(-2.135)\end{array}$ & $\begin{array}{r}-0.00695 \\
(-0.898)\end{array}$ \\
\hline COGS & $\begin{array}{l}0.000533^{* * *} \\
(2.809)\end{array}$ & $\begin{array}{c}0.000365 \\
(0.667)\end{array}$ \\
\hline RDExp & $\begin{array}{c}-0.000962^{* * *} \\
(-3.216)\end{array}$ & $\begin{array}{c}0.000235 \\
(0.349)\end{array}$ \\
\hline CAPX & $\begin{array}{c}0.00363 \\
(0.764)\end{array}$ & $\begin{array}{c}-0.00765 \\
(-0.586)\end{array}$ \\
\hline HHIInd & $\begin{array}{l}-0.0965 \\
(-0.584)\end{array}$ & $\begin{array}{c}0.331 \\
(0.312)\end{array}$ \\
\hline Leverage & $\begin{array}{c}-0.00338 * * * \\
(-7.358)\end{array}$ & $\begin{array}{c}-0.00503 * * * \\
(-5.605)\end{array}$ \\
\hline CashFlow & $\begin{array}{c}-0.00235 \\
(-1.018)\end{array}$ & $\begin{array}{r}-0.00177 \\
(-0.442)\end{array}$ \\
\hline \multicolumn{3}{|c|}{ Panel B. Average Treatment Effects } \\
\hline Treatment group: the demeaned $M F 1$ & above the 90th & tile of the period \\
\hline Dependent Variable & SaleToAst & SVIShop \\
\hline Match based on characteristics & $\begin{array}{c}-0.329^{* * *} \\
(-4.851)\end{array}$ & $\begin{array}{c}-0.750^{* * *} \\
(-3.732)\end{array}$ \\
\hline $\begin{array}{l}\text { Match based on characteristics } \\
\text { within the same industry and period }\end{array}$ & $\begin{array}{c}-0.194^{* * *} \\
(-2.700)\end{array}$ & $\begin{array}{c}-0.625 * * * \\
(-3.027)\end{array}$ \\
\hline Linear model & $\begin{array}{c}-0.279 * * * \\
(-3.585)\end{array}$ & $\begin{array}{c}-0.870 * * * \\
(-4.180)\end{array}$ \\
\hline
\end{tabular}




\section{Table 8: Robustness Tests}

This table examines whether the main empirical results shown in the paper are robust to alternative specifications. All regressions are 2SLS, in which Return or $Q$ is instrumented by MFFlow. In Panel A, the unit of observation is firm-quarter. Control variables (untabulated in the table for brevity) include $\log (A g e), \log (M k t C a p), A d E x p, C O G S$, RDExp, CAPX, HHIInd, Leverage, and CashFlow. In Panel B, the unit of observation is firm-month. Control variables (untabulated in the table for brevity) include SVIFin $(\log (1+$ SVIFin $)$ in column (3)) $\log (1+$ NewsNum $)$, and all controls used in Panel A. Return and MFFlow are concurrent to the dependent variable, while control variables are lagged by one period. $\log ($ Sales $), Q$, and $\log (1+$ SVIShop $)$ are multiplied by 100 for ease of interpretation. I present the $t$-statistics in the parentheses. ${ }^{* * *},{ }^{* *}$, and ${ }^{*}$ denote statistical significance at the $1 \%, 5 \%$, and $10 \%$ levels, respectively.

\begin{tabular}{|c|c|c|c|c|c|}
\hline \multicolumn{6}{|c|}{ Panel A. Sales Regressions } \\
\hline & (1) & $(2)$ & $(3)$ & $(4)$ & $(5)$ \\
\hline Dependent Variable & SaleToAst & SaleToAst & SaleToAst & $\log$ (Sales) & SaleToAst \\
\hline Return & $\begin{array}{c}0.0844^{* * *} \\
(5.286)\end{array}$ & $\begin{array}{c}0.0597^{* * *} \\
(3.405)\end{array}$ & $\begin{array}{c}0.0699^{* * * *} \\
(5.516)\end{array}$ & $\begin{array}{c}0.302^{* * *} \\
(4.342)\end{array}$ & \\
\hline Q & & & & & $\begin{array}{c}0.0485^{* * *} \\
(5.246)\end{array}$ \\
\hline Observations & 311,368 & 311,368 & 311,368 & 311,368 & 311,368 \\
\hline R-squared & 0.850 & 0.833 & 0.822 & 0.960 & 0.825 \\
\hline Firm FE & SUBSUMED & YES & YES & YES & YES \\
\hline Time FE & YES & SUBSUMED & YES & YES & YES \\
\hline Firm $\times$ QofY FE & YES & NO & NO & NO & NO \\
\hline Ind $\times$ Time $\mathrm{FE}$ & NO & YES & NO & NO & $\mathrm{NO}$ \\
\hline SE Cluster & Industry & Industry & Firm & Industry & Industry \\
\hline \multicolumn{6}{|c|}{ Panel B. Online Customer Interest Regressions } \\
\hline & $(1)$ & $(2)$ & $(3)$ & (4) & (5) \\
\hline Dependent Variable & SVIShop & SVIShop & SVIShop & $\log$ (SVIShop) & SVIShop \\
\hline Return & $\begin{array}{c}0.207^{* * *} \\
(3.006)\end{array}$ & $\begin{array}{l}0.129^{*} \\
(1.870)\end{array}$ & $\begin{array}{c}0.151^{* *} \\
(2.403)\end{array}$ & $\begin{array}{c}0.464^{* *} \\
(2.017)\end{array}$ & \\
\hline Q & & & & & $\begin{array}{c}0.0977^{* *} \\
(2.283)\end{array}$ \\
\hline Observations & 167,895 & 167,895 & 167,895 & 167,895 & 167,895 \\
\hline R-squared & 0.544 & 0.524 & 0.503 & 0.445 & 0.440 \\
\hline Firm FE & SUBSUMED & YES & YES & YES & YES \\
\hline Time FE & YES & SUBSUMED & YES & YES & YES \\
\hline Firm $\times$ MofY FE & YES & NO & NO & NO & NO \\
\hline Ind $\times$ Time FE & $\mathrm{NO}$ & YES & $\mathrm{NO}$ & $\mathrm{NO}$ & $\mathrm{NO}$ \\
\hline SE Cluster & Industry & Industry & Firm & Industry & Industry \\
\hline
\end{tabular}




\section{Table 9: Alternative Explanations}

This table examines whether the effects of stock returns on sales (Panel A) and online customer interest (Panel B) hold after removing the most financially constrained or distressed firms, or recessionary periods. The unit of observation is firm-quarter in Panel A and firm-month in Panel B. All regressions are estimated using the 2SLS method. In the first column, I use the financial constraint index proposed in Kaplan and Zingales (1997) and remove observations with index values in the top three deciles. In the second column, I use the financial constraint index proposed in Whited and $\mathrm{Wu}$ (2006) and remove observations with index values in the top three deciles. In the third column, I use the z-score for financial distress proposed in Altman (1968) and remove observations with z-score values in the bottom three deciles. In the last column, I remove NBER recessionary periods. Return is instrumented by MFFlow. In Panel A, control variables (untabulated in the table for brevity) include $\log (A g e), \log (M k t C a p)$, AdExp, COGS, RDExp, CAPX, HHIInd, Leverage, and CashFlow. In Panel B, control variables include SVIFin, $\log (1+N e w s N u m)$, and all controls used in Panel A. I present the $t$-statistics in the parentheses. Standard errors are clustered by industry. ${ }^{* * *},{ }^{* *}$, and ${ }^{*}$ denote statistical significance at the $1 \%, 5 \%$, and $10 \%$ levels, respectively.

\begin{tabular}{|c|c|c|c|c|}
\hline \multicolumn{5}{|c|}{ Panel A. Sales Regressions } \\
\hline & $(1)$ & $(2)$ & $(3)$ & $(4)$ \\
\hline Sample Exclusion & High KZ & High WW & Low A-Z & Recession \\
\hline Dependent Variable & SaleToAst & SaleToAst & SaleToAst & SaleToAst \\
\hline Return & $\begin{array}{c}0.0848^{* * *} \\
(5.101)\end{array}$ & $\begin{array}{c}0.0463^{* * *} \\
(4.067)\end{array}$ & $\begin{array}{c}0.0925^{* * *} \\
(6.211)\end{array}$ & $\begin{array}{c}0.0705^{* * *} \\
(4.141)\end{array}$ \\
\hline Observations & 217,594 & 217,489 & 217,634 & 270,075 \\
\hline R-squared & 0.834 & 0.847 & 0.839 & 0.822 \\
\hline Controls & YES & YES & YES & YES \\
\hline Firm FE & YES & YES & YES & YES \\
\hline Time FE & YES & YES & YES & YES \\
\hline \multicolumn{5}{|c|}{ Panel B. Online Customer Interest Regressions } \\
\hline & $(1)$ & $(2)$ & $(3)$ & (4) \\
\hline Sample Exclusion & High KZ & High WW & Low A-z & Recession \\
\hline Dependent Variable & SVIShop & SVIShop & SVIShop & SVIShop \\
\hline Return & $\begin{array}{c}0.141^{* *} \\
(2.092)\end{array}$ & $\begin{array}{c}0.154^{*} \\
(1.951)\end{array}$ & $\begin{array}{c}0.319^{* * *} \\
(3.901)\end{array}$ & $\begin{array}{c}0.200^{* *} \\
(2.355)\end{array}$ \\
\hline Observations & 115,713 & 115,711 & 115,703 & 140,197 \\
\hline R-squared & 0.521 & 0.536 & 0.496 & 0.492 \\
\hline Controls & YES & YES & YES & YES \\
\hline Firm FE & YES & YES & YES & YES \\
\hline Time FE & YES & YES & YES & YES \\
\hline
\end{tabular}




\section{Table 10: Effects of Stock Returns on Product Launch Probability}

This table examines whether firms are less likely to launch new products when their stock returns are lower. The unit of observation is firm-month. I present the $t$-statistics in the parentheses. Standard errors are clustered by industry. $* * *, * *$, and $*$ denote statistical significance at the $1 \%, 5 \%$, and $10 \%$ levels, respectively. The coefficients are multiplied by 100 for ease of interpretation.

\begin{tabular}{|c|c|c|c|c|}
\hline & \multirow{3}{*}{$\frac{(1)}{\text { OLS }}$} & $(2)$ & $(3)$ & $(4)$ \\
\hline & & \multicolumn{2}{|c|}{$2 \mathrm{SLS}$} & Reduced Form \\
\hline & & 1st Stage & 2nd Stage & \\
\hline Dependent Variable & $\begin{array}{c}\text { Prod- } \\
\text { LauDum }\end{array}$ & Return & $\begin{array}{c}\text { Prod- } \\
\text { LauDum }\end{array}$ & ProdLauDum \\
\hline Return & $\begin{array}{c}0.0197^{* * * *} \\
(4.329)\end{array}$ & & $\begin{array}{c}0.0886^{* *} \\
(2.247)\end{array}$ & \\
\hline MFFlow & & $\begin{array}{c}-0.937^{* * *} \\
(-18.29)\end{array}$ & & $\begin{array}{c}-0.0830^{* *} \\
(-2.285)\end{array}$ \\
\hline $\log ($ Age $)$ & $\begin{array}{c}6.527^{* * *} \\
(3.904)\end{array}$ & $\begin{array}{c}0.118 \\
(0.638)\end{array}$ & $\begin{array}{c}6.519^{* * *} \\
(3.915)\end{array}$ & $\begin{array}{c}6.530^{* * *} \\
(3.897)\end{array}$ \\
\hline $\log ($ MktCap) & $\begin{array}{c}0.811^{* * *} \\
(3.247)\end{array}$ & $\begin{array}{c}-3.753^{* * *} \\
(-25.89)\end{array}$ & $\begin{array}{c}1.071^{* * *} \\
(3.946)\end{array}$ & $\begin{array}{c}0.738^{* * *} \\
(3.043)\end{array}$ \\
\hline AdExp & $\begin{array}{l}-0.0182 \\
(-0.309)\end{array}$ & $\begin{array}{c}-0.00485 \\
(-0.259)\end{array}$ & $\begin{array}{l}-0.0178 \\
(-0.298)\end{array}$ & $\begin{array}{l}-0.0182 \\
(-0.308)\end{array}$ \\
\hline COGS & $\begin{array}{c}-0.000703 \\
(-0.984)\end{array}$ & $\begin{array}{c}-0.00220^{* * *} \\
(-4.045)\end{array}$ & $\begin{array}{c}-0.000555 \\
(-0.754)\end{array}$ & $\begin{array}{c}-0.000750 \\
(-1.061)\end{array}$ \\
\hline RDExp & $\begin{array}{c}0.00256^{* *} \\
(2.214)\end{array}$ & $\begin{array}{c}0.00445^{* * *} \\
(4.771)\end{array}$ & $\begin{array}{c}0.00225^{*} \\
(1.962)\end{array}$ & $\begin{array}{c}0.00265^{* *} \\
(2.300)\end{array}$ \\
\hline CAPX & $\begin{array}{l}0.0497 \\
(1.087)\end{array}$ & $\begin{array}{c}-0.114^{* * *} \\
(-4.144)\end{array}$ & $\begin{array}{l}0.0570 \\
(1.215)\end{array}$ & $\begin{array}{l}0.0468 \\
(1.033)\end{array}$ \\
\hline Leverage & $\begin{array}{c}0.0277^{* * * *} \\
(3.141)\end{array}$ & $\begin{array}{c}-0.0197 * * * \\
(-4.899)\end{array}$ & $\begin{array}{c}0.0289^{* * *} \\
(3.189)\end{array}$ & $\begin{array}{c}0.0272^{* * * *} \\
(3.104)\end{array}$ \\
\hline CashFlow & $\begin{array}{l}-0.0302 \\
(-1.341)\end{array}$ & $\begin{array}{c}0.305^{* * *} \\
(13.88)\end{array}$ & $\begin{array}{c}-0.0515^{*} \\
(-1.955)\end{array}$ & $\begin{array}{l}-0.0245 \\
(-1.119)\end{array}$ \\
\hline HHIInd & $\begin{array}{c}8.850^{* *} \\
(2.337)\end{array}$ & $\begin{array}{c}-0.634 \\
(-0.344)\end{array}$ & $\begin{array}{c}8.861^{* *} \\
(2.319)\end{array}$ & $\begin{array}{c}8.805^{* *} \\
(2.329)\end{array}$ \\
\hline Observations & 299,521 & 299,521 & 299,521 & 299,521 \\
\hline R-squared & 0.305 & 0.227 & 0.304 & 0.305 \\
\hline Firm FE & YES & YES & YES & YES \\
\hline Time FE & YES & YES & YES & YES \\
\hline
\end{tabular}


Appendices 


\section{Appendix A}

\section{Proofs}

\section{Proof of Proposition 1}

I use a guess-and-verify method to solve for the stock prices. Suppose that $p=A+B z+C x$, for some constants $A, B$, and $C$. The signal on $z$ derived from $p$ is $\zeta=\frac{p-A}{B}=z+\frac{C}{B} x$. Substituting the equations in (2.4) into the optimal demand for the firm's stock in equation (2.3) and using the market clearing condition (2.5) lead to the following expression for $p$ :

$$
p=\frac{v_{z}^{-1} \bar{z}+v_{\zeta}^{-1} \zeta+v_{\eta}^{-1} z}{v_{z}^{-1}+v_{\zeta}^{-1}+v_{\eta}^{-1}}-\frac{a v_{\eta}^{-1}(\bar{x}+x)}{\left(v_{z}^{-1}+v_{\zeta}^{-1}+v_{\eta}^{-1}\right)^{2}} .
$$

$A, B$, and $C$ are solved by matching coefficients:

$$
\begin{gathered}
A=\frac{v_{z}^{-1} \bar{z}}{v_{z}^{-1}+v_{\zeta}^{-1}+v_{\eta}^{-1}}-\frac{a v_{\eta}^{-1} \bar{x}}{\left(v_{z}^{-1}+v_{\zeta}^{-1}+v_{\eta}^{-1}\right)^{2}} \\
B=\frac{v_{\zeta}^{-1}+v_{\eta}^{-1}}{v_{z}^{-1}+v_{\zeta}^{-1}+v_{\eta}^{-1}} ; \\
C=\frac{v_{\zeta}^{-1} \frac{C}{B}}{v_{z}^{-1}+v_{\zeta}^{-1}+v_{\eta}^{-1}}-\frac{a v_{\eta}^{-1}}{\left(v_{z}^{-1}+v_{\zeta}^{-1}+v_{\eta}^{-1}\right)^{2}}
\end{gathered}
$$

Dividing $C$ by $B$ and simplifying give

$$
\frac{C}{B}=-\frac{a}{v_{z}^{-1}+v_{\eta}^{-1}+v_{\zeta}^{-1}} .
$$


Substituting equation (1.5) into equation (1.4) gives

$$
C=-\frac{a\left(v_{\zeta}^{-1}+v_{\eta}^{-1}\right)}{\left(v_{z}^{-1}+v_{\zeta}^{-1}+v_{\eta}^{-1}\right)^{2}} .
$$

Note that

$$
v_{\zeta}=\left(\frac{C}{B}\right)^{2} v_{x}
$$

Substituting equation (1.7) into equation (1.5) and rearranging suggest that $\frac{C}{B}$ solves the following quadratic equation:

$$
\left(v_{z}^{-1}+v_{\eta}^{-1}\right)\left(\frac{C}{B}\right)^{2}+a \frac{C}{B}+v_{x}^{-1}=0
$$

I restrict attention to the set of parameters for which the solution to equation (1.8) exists, that is, $a^{2}-4\left(v_{z}^{-1}+v_{\eta}^{-1}\right) v_{x}^{-1} \geq 0$. Hence,

$$
\frac{C_{1}}{B_{1}}=\frac{-a+\sqrt{a^{2}-4\left(v_{z}^{-1}+v_{\eta}^{-1}\right) v_{x}^{-1}}}{2\left(v_{z}^{-1}+v_{\eta}^{-1}\right)}
$$

or

$$
\frac{C_{2}}{B_{2}}=\frac{-a-\sqrt{a^{2}-4\left(v_{z}^{-1}+v_{\eta}^{-1}\right) v_{x}^{-1}}}{2\left(v_{z}^{-1}+v_{\eta}^{-1}\right)}
$$

Substituting equation (1.9) or (1.10) back into equation (1.7) gives $v_{\zeta}$.

\section{Proof of Proposition 2 and the Model without Cus- tomer Learning from Stock Prices}

Substituting $\zeta=z+\frac{C}{B} x$ into equation (2.2) gives

$$
f=\frac{v_{z}^{-1} \bar{z}+v_{\eta}^{-1} \eta}{v_{z}^{-1}+v_{\zeta}^{-1}+v_{\eta}^{-1}}+\frac{v_{\zeta}^{-1}}{v_{z}^{-1}+v_{\zeta}^{-1}+v_{\eta}^{-1}}\left(z+\frac{C}{B} x\right)
$$


In both linear equilibria,

$$
\frac{\partial f}{\partial x}=\frac{v_{\zeta}^{-1}}{v_{z}^{-1}+v_{\eta}^{-1}+v_{\zeta}^{-1}} \frac{C}{B}=-a^{-1} v_{x}^{-1}<0 .
$$

Therefore, Proposition 2 holds.

If the customer does not use the signal derived from the stock price, then the firm's cash flow becomes

$$
f^{\prime}=\frac{v_{z}^{-1} \bar{z}+v_{\eta}^{-1} \eta}{v_{z}^{-1}+v_{\eta}^{-1}}=\frac{v_{z}^{-1} \bar{z}+v_{\eta}^{-1}\left(z+\epsilon_{\eta}\right)}{v_{z}^{-1}+v_{\eta}^{-1}} .
$$

The speculators' conditional expectation and variance of $f^{\prime}$ are

$$
E\left[f^{\prime} \mid z\right]=\frac{v_{z}^{-1} \bar{z}+v_{\eta}^{-1} z}{v_{z}^{-1}+v_{\eta}^{-1}} ; \quad V\left[f^{\prime} \mid z\right]=\frac{v_{\eta}^{-1}}{\left(v_{z}^{-1}+v_{\eta}^{-1}\right)^{2}}
$$

Substituting equations in (2.4) into the optimal stock demand in equation (2.3) and using the market clearing condition (2.5) give the following solution of $p^{\prime}$ :

$$
p^{\prime}=\frac{v_{\eta}^{-1}}{v_{z}^{-1}+v_{\eta}^{-1}} z-\frac{a v_{\eta}^{-1}}{\left(v_{z}^{-1}+v_{\eta}^{-1}\right)^{2}} x+\frac{v_{z}^{-1} \bar{z}}{v_{z}^{-1}+v_{\eta}^{-1}}-\frac{a v_{\eta}^{-1} \bar{x}}{\left(v_{z}^{-1}+v_{\eta}^{-1}\right)^{2}} .
$$

When the customer does not learn from the stock price, there is a unique linear equilibrium. The customer demand (i.e., the firm's cash flow) is still correlated with the stock price because $z$ enters both $f^{\prime}$ and $p^{\prime}$. However, $f^{\prime}$ does not depend on the noise trader shock $x$. Hence, the prediction that customer demand decreases in the noisy supply of the firm's stock only holds in a model with customer learning from stock prices. 


\section{Proof of Corollary 1}

Equation (2.6) can be rewritten as

$$
\operatorname{Prob}[L=1]= \begin{cases}0 & \text { if } E[g \mid z]<\underline{k} \\ \frac{v_{z}^{-1} \bar{z}+v_{\eta}^{-1} z+v_{\zeta}^{-1} \zeta}{(\bar{k}-\underline{k})\left(v_{z}^{-1}+v_{\zeta}^{-1}+v_{\eta}^{-1}\right)}-\frac{\underline{k}}{\bar{k}-\underline{k}} & \text { if } \underline{k} \leq E[g \mid z]<\bar{k} \\ 1 & \text { if } E[g \mid z] \geq \bar{k}\end{cases}
$$

In both linear equilibria,

$$
\frac{\partial \operatorname{Prob}[L=1]}{\partial x}= \begin{cases}\frac{v_{\zeta}^{-1} \frac{C}{B}}{(\bar{k}-\underline{k})\left(v_{z}^{-1}+v_{\zeta}^{-1}+v_{\eta}^{-1}\right)}=-a^{-1} v_{x}^{-1}(\bar{k}-\underline{k})^{-1}<0 & \text { if } \underline{k} \leq E[g \mid z]<\bar{k} \\ 0 & \text { otherwise }\end{cases}
$$

Therefore, Corollary 1 holds.

\section{Proof of Proposition 3}

The unconditional variance of $E[g \mid z]$ can be expressed as

$$
V[E[g \mid z]]=\left(\frac{v_{\eta}^{-1}}{v_{z}^{-1}+v_{\zeta}^{-1}+v_{\eta}^{-1}}\right)^{2} v_{z}+\left(\frac{v_{\zeta}^{-1}}{v_{z}^{-1}+v_{\zeta}^{-1}+v_{\eta}^{-1}}\right)^{2}\left(v_{\zeta}+v_{z}\right) .
$$

Let $V_{1}[E[g \mid z]]$ denote the variance obtained by substituting equation (1.9) into (4.1), and $V_{2}[E[g \mid z]]$ denote that obtained by substituting equation (1.10) into equation (4.1).

$$
V_{1}[E[g \mid z]]-V_{2}[E[g \mid z]]=\frac{v_{\eta} v_{z}\left(v_{\eta}+2 v_{z}\right) \sqrt{a^{2}-4\left(v_{z}^{-1}+v_{\eta}^{-1}\right) v_{x}^{-1}}}{a\left(v_{\eta}+v_{z}\right)^{2}}>0
$$

Therefore, this variance is greater in equilibrium 1 (i.e., the one characterized in equation (1.9)). The ex ante expected net cash flow of the product launch is given in equation (2.7). This quantity is increasing in $V[E[g \mid z]]$ given that 
$E[g \mid z]$ is normally distributed. Furthermore, the unconditional mean of $E[g \mid z]$ is $\bar{z}$ in both equilibria. Thus, the ex ante expected cash flow is greater in equilibrium 1. 


\section{Appendix B}

\section{Data Details}

\section{Google Trends Data Collection}

I use an automated script to collect the search volume indexes (SVI) from Google Trends. To capture the online customer interest in a company, I obtain the SVI on the Google topic of a given company in the category "shopping". Specifically, I first remove all commonly used words (e.g., "inc", "corp", "co", and "group") from the company names reported in Compustat.

Next, I use the stripped company names as search inputs to collect all topics suggested by Google and select topics categorized as "company", "business operation", "corporation", or words with similar meanings. I keep the first topic when more than one company-level topics are available (usually due to redundant topics or subsidiaries). Lastly, all downloads are manually checked to ensure that the company names and Google topics are correctly matched. Some company names are not linked to Google search topics. When a search topic is unavailable, I collect the SVI using the stripped company name as the input. In the regression sample, $89.9 \%$ of the observations are obtained using the topic report function. To identify the customer interest separately from other types of interest, I restrict the index to the category "shopping". 
There are some caveats regarding the Google Trends data. First, Google Trends does not report the actual search frequencies, but rather provide an index scaled between 0 and 100. Within each download, the data point that has the highest (lowest) actual search frequency is assigned with an index value of $100(0)$. The problem with this data structure is that the index values across different downloads are not comparable. Since I download the index for each firm separately, firm fixed effects are included in all regressions to address this problem. The second caveat is that to increase response speed, Google Trends does not use all historical search data in Google's system to compute the SVIs. Instead, a random representative sample is used. These sampling errors add noise to my estimation, but are unlikely to cause any directional biases. Lastly, the SVI from Google Trends are bottom-coded. Specifically, if the search volume is below a certain threshold, the index value is coded as zero. I require each sample firm to have at least $60 \%$ non-zero monthly observations during my sample period to be included in the regression analysis. Da et al. (2011) imposes a similar restriction in their study. In the final sample, a valid shopping-related search volume index is available for $52 \%$ of the firm-month observations that have non-missing values for all CRSP and Compustat variables required in the main regressions.

\section{Construction of the Instrument MFFlow}

Mutual fund holdings data are obtained from Thomson Reuters mutual fund common stock holdings database. Following Coval and Stafford (2007), 
I exclude funds with the following Investment Objective Codes: international, municipal bonds, bond and preferred, or metals. Data on mutual fund returns and assets under management are from CRSP survivor-bias-free US mutual fund database. I use the investment style variables in CRSP to identify sector funds and exclude them from the analysis. Specifically, I remove funds with Lipper classification codes AU, H, FS, NR, RE, TK, UT, CG, CMD, CS, ID, BM, or TL, or Strategic Insight codes GLD, HLT, FIN, NTR, RLE, TEC, UTI, or SEC, or Wiesenberger objective codes GPM, HLT, FIN, ENR, TCH, or UTL. The CRSP mutual fund database and the Thomson Reuters holdings database are merged using MFLINKS constructed in Wermers (2000). Data on stock prices and trading volume are from CRSP monthly stock files.

To construct MFFlow, I first identify funds that experience extreme outflows in the previous period. The percentage flow of the fund $f$ in period $t$ is

$$
\text { Flow }_{f, t}=\frac{T N A_{f, t}-T N A_{f, t-1}\left(1+r_{f, t}\right)}{T N A_{f, t-1}},
$$

where $T N A_{f, t}$ is the assets under management of fund $f$ in period $t$ and $r_{f, t}$ is the net return of fund $f$ in period $t$. A fund is considered to have experienced extreme outflows when Flow $f, t$ is less than the tenth percentile of the entire sample. The rest of the definition of MFFlow is given in the paper.

\section{RavenPack News Analytics}

This paper uses two editions of RavenPack News Analytics. The Dow Jones edition compiles news reports and press releases from 2000 to 2014 
published by Dow Jones Newswires, all editions of the Wall Street Journal, Barron's and MarketWatch. The PR edition includes firms' press releases from 2004 to 2014 published in 22 different newswires and press release distribution networks. My sample period starts in 2004 because during the first four years the coverage of press releases is very limited and the Google Trends data starts in 2004. RavenPack Event Taxonomy classifies corporate events into detailed categories. The hierarchy of the taxonomy, from the highest level to the lowest level, consists of "topic", "group", "type", and "sub-type". To measure firms' product launch decisions, I use press releases in the type of "product-release", which include launches of new products or services or upgrades to existing ones. Events with sub-type "delayed" are excluded.

RavenPack also provides a relevance score and a novelty score for each press release-firm pair to summarize how related the firm is to the underlying story and how novel the story is compared with previously reported stories. The relevance and novelty scores range from 0 to 100, with 100 being the most relevant/novel. I use the press releases of new products and services with relevance and novelty scores both being 100. Selecting news items with the highest possible relevance score reduces the noise in the data because a company may be mentioned in a product press release, but is not the announcing company. The novelty score filter avoids counting the same announcement multiple times. RavenPack compiles press releases from multiple sources. Since the same event may be covered by different sources, simply counting the number of releases would not be equivalent to the number of new products. To mitigate this 
problem, I only select the news items with a novelty score of 100, meaning that no similar news has been reported before. 


\section{Bibliography}

Altman, E. I. 1968. Financial ratios, discriminant analysis and the prediction of corporate bankruptcy. The Journal of Finance 23:589-609.

Bai, J., T. Philippon, and A. Savov. 2016. Have financial markets become more informative? Journal of Financial Economics, Forthcoming.

Baker, M., J. C. Stein, and J. Wurgler. 2003. When does the market matter? Stock prices and the investment of equity-dependent firms. Quarterly Journal of Economics 118:969-1005.

Bakke, T.-E., and T. M. Whited. 2010. Which firms follow the market? An analysis of corporate investment decisions. Review of Financial Studies 23:1941-1980.

Bond, P., A. Edmans, and I. Goldstein. 2012. The real effects of financial markets. Annual Review of Financial Economics 4:339-360.

Chen, Q., I. Goldstein, and W. Jiang. 2007. Price informativeness and investment sensitivity to stock price. Review of Financial Studies 20:619-650.

Coval, J., and E. Stafford. 2007. Asset fire sales (and purchases) in equity markets. Journal of Financial Economics 86:479-512. 
Da, Z., J. Engelberg, and P. Gao. 2011. In search of attention. Journal of Finance 66:1461-1499.

Daniel, K., M. Grinblatt, S. Titman, and R. Wermers. 1997. Measuring mutual fund performance with characteristic-based benchmarks. Journal of Finance $52: 1035-1058$.

Dessaint, O., T. Foucault, L. Frésard, and A. Matray. 2016. Ripple Effects of Noise on Corporate Investment. Working paper, University of Toronto .

Dow, J., and G. Gorton. 1997. Stock market efficiency and economic efficiency: Is there a connection? Journal of Finance 52:1087-1129.

Edmans, A., I. Goldstein, and W. Jiang. 2012. The real effects of financial markets: The impact of prices on takeovers. Journal of Finance 67:933-971.

Edmans, A., I. Goldstein, and W. Jiang. 2015. Feedback effects, asymmetric trading, and the limits to arbitrage. American Economic Review 105:37663797.

Edmans, A., S. Jayaraman, and J. Schneemeier. 2016. The source of information in prices and investment-price sensitivity. Journal of Financial Economics, Forthcoming.

Foucault, T., and L. Frésard. 2012. Cross-listing, investment sensitivity to stock price, and the learning hypothesis. Review of Financial Studies $25: 3305-3350$. 
Foucault, T., and L. Fresard. 2014. Learning from peers' stock prices and corporate investment. Journal of Financial Economics 111:554-577.

Foucault, T., and T. Gehrig. 2008. Stock price informativeness, cross-listings, and investment decisions. Journal of Financial Economics 88:146-168.

Goldstein, I., and A. Guembel. 2008. Manipulation and the allocational role of prices. Review of Economic Studies 75:133-164.

Goldstein, I., E. Ozdenoren, and K. Yuan. 2013. Trading frenzies and their impact on real investment. Journal of Financial Economics 109:566-582.

Grossman, S. J., and J. E. Stiglitz. 1980. On the impossibility of informationally efficient markets. American Economic Review 70:393-408.

Hau, H., and S. Lai. 2013. Real effects of stock underpricing. Journal of Financial Economics 108:392-408.

Hayek, F. A. 1945. The use of knowledge in society. American Economic Review 35:519-530.

Hortaçsu, A., G. Matvos, C. Syverson, and S. Venkataraman. 2013. Indirect costs of financial distress in durable goods industries: The case of auto manufacturers. Review of Financial Studies 26:1248-1290.

Hu, Y., R. Y. Du, and S. Damangir. 2014. Decomposing the impact of advertising: Augmenting sales with online search data. Journal of Marketing Research 51:300-319. 
Huang, S., M. Ringgenberg, and Z. Zhang. 2016. The Information in Fire Sales, Working paper, Washington University in St. Louis.

Kaplan, S. N., and L. Zingales. 1997. Do investment-cash flow sensitivities provide useful measures of financing constraints? Quarterly Journal of Economics 112:169-215.

Khan, M., L. Kogan, and G. Serafeim. 2012. Mutual fund trading pressure: Firm-Level stock price impact and timing of SEOs. Journal of Finance 67:1371-1395.

Khanna, N., and R. Sonti. 2004. Value creating stock manipulation: Feedback effect of stock prices on firm value. Journal of Financial Markets 7:237-270.

Lou, D. 2012. A flow-based explanation for return predictability. Review of Financial Studies 25:3457-3489.

Luo, Y. 2005. Do insiders learn from outsiders? Evidence from mergers and acquisitions. Journal of Finance 60:1951-1982.

Madsen, J., and M. Niessner. 2016. Is investor attention for sale? The role of advertising in financial markets. Working paper, University of Minnesota.

Markovitch, D. G., J. H. Steckel, and B. Yeung. 2005. Using capital markets as market intelligence: Evidence from the pharmaceutical industry. Management Science 51:1467-1480. 
Peress, J. 2014. Learning from stock prices and economic growth. Review of Financial Studies 27:2998-3059.

Sockin, M. 2015. Not so great expectations: A model of growth and informational frictions, Working paper, UT Austin.

Stoughton, N., K. P. Wong, and J. Zechner. 2001. IPOs and product quality. Journal of Business 74:375-408.

Subrahmanyam, A., and S. Titman. 1999. The going-public decision and the development of financial markets. Journal of Finance 54:1045-1082.

Subrahmanyam, A., and S. Titman. 2001. Feedback from stock prices to cash flows. Journal of Finance 56:2389-2413.

Subrahmanyam, A., and S. Titman. 2013. Financial market shocks and the macroeconomy. Review of Financial Studies 26:2687-2717.

Wermers, R. 2000. Mutual fund performance: An empirical decomposition into stock-picking talent, style, transactions costs, and expenses. Journal of Finance 55:1655-1703.

Whited, T. M., and G. Wu. 2006. Financial constraints risk. Review of Financial Studies 19:531-559.

Williams, R., and S. C. Xiao. 2016. The effect of stock prices on real investment in the vertical supply chain, Working paper, University of Arizona. 
Wooldridge, J. M. 2010. Econometric analysis of cross section and panel data. MIT Press. 


\section{Vita}

Sophia Yue Sun was born in Qingdao, China on June 16, 1989, the daughter of Jingwen Sun and Wenhao Du. She received the Bachelor of Business Administration degree in Finance and Economics from Baylor University in May 2011. In August 2011, she entered the Finance Ph.D. Program at the McCombs School of Business.

Permanent address: 47 Qutangxia Road, Apt. 2003

Qingdao, China 266002 